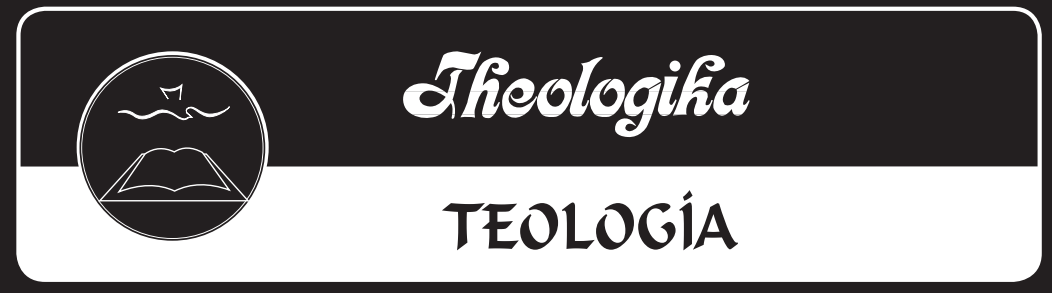

\title{
De la visión al sistema: terminando la tarea de la teología adventista bíblica y sistemática - parte II
}


Fernando Ganale 


\section{RESUMEN}

“De la visión al sistema: terminando la tarea de la teología adventista bíblica y sistemática" - parte II - En el primer artículo, de esta serie, se trazaron los cambios más sobresalientes en el desarrollo de la visión hermenéutica adventista, desde sus orígenes hasta el presente. Al resumirlo, se puso de manifiesto algunos hechos importantes sobre la forma como los adventistas hacen teología. Para los primeros adventistas la doctrina del Santuario se tornó en la visión hermenéutica que orientó el descubrimiento de un sistema completo de teología y verdad. Este sistema de teología, a su vez, guió la práctica del ministerio y condujo a la Iglesia Adventista hacia su crecimiento y expansión mundial. En esta parte, el autor muestra que los adventistas han hecho de la historia algo esencial, no solamente para el entendimiento de la profecía, sino también para la comprensión de las enseñanzas cristianas. Además señala que, en la interpretación profética, los adventistas bíblicos e históricos todavía trabajan dentro de una tradición interpretativa historicista. Igualmente muestra que, teológicamente, los adventistas también piensan históricamente desde el interior de la dinámica del Gran Conflicto. Con esto asumen que la presencia histórica de Dios es real, actuando directamente dentro del flujo espacio-temporal de la historia humana. $Y$, en esto, el autor no solo muestra que ninguna otra tradición o escuela de teología cristiana comparte la visión adventista sobre la interpretación profética y la matriz del Gran Conflicto para la teología sistemática, sino que también muestra que hay razones metodológicas detrás de este enfoque único en la teología cristiana.

Palabras clave: Textualidad, cosmovisón. 


\section{ABSTRACT}

\section{"From Vision to the System: Finishing the Task of Bi-}

blical and Systematic Adventist Theology" - Part II - In the first article of this series, the most significant changes were traced in the development of the Adventist hermeneutical view from its origins to the present. In summary some important facts about how Adventists do theology were revealed. For early Adventists the sanctuary doctrine turned into the hermeneutical vision that oriented the discovery of a complete system of theology and truth. This system of theology, in turn, led to the practice of ministry and to the Adventist Church's growth and global expansion. In this part, the author shows that Adventists have made something essential from history not only for the understanding of prophecy but also for understanding Christian teachings. He further states that in prophetic interpretation, biblical and historic Adventists still work within an historicist interpretive tradition. In the same way he shows that theologically, Adventists also think historically from within the dynamics of the Great Controversy. With this they assume that the historical presence of God is real acting directly within the spatial-temporal flow of the human history. And in this, the author not only shows that no other tradition or school of Christian theology shares the Adventist vision on the prophetic interpretation and the matrix of the Great Controversy for systematic theology, but also shows that there are methodological reasons behind this approach that is unique in Christian theology.

Keywords: Textuality, cosmovison. 


\section{DE LA VISIÓN AL SISTEMA: TERMINANDO LA TAREA DE LA TEOLOGÍA ADVENTISTA BÍBLICA Y SISTEMÁTICA - PARTE II}

En el primer artículo, de esta serie, se trazaron los cambios más sobresalientes en el desarrollo de la visión hermenéutica adventista, desde sus orígenes hasta el presente. Este resumen general puso de manifiesto algunos hechos importantes sobre la forma cómo los adventistas hacen teología. Para los primeros adventistas la doctrina del Santuario se tornó en la visión hermenéutica que orientó el descubrimiento de un sistema completo de teología y verdad. Este sistema de teología, a su vez, guió la práctica del ministerio y condujo a la Iglesia Adventista hacia su crecimiento y expansión mundial.

\section{Revisión}

Durante la segunda mitad del siglo XX, el adventismo evangélico rechazó la doctrina del Santuario debido a que contradecía su comprensión teológica de la justificación por la fe, delineada a partir del sistema protestante de teología. En consecuencia, abandonaron la interpretación profética historicista de los pioneros, la doctrina del Santuario y el entendimiento de la salvación como un proceso histórico. En pocas palabras, este sector del adventismo se convenció de que la interpretación profética de nuestros pioneros y la comprensión escatológica de la teología estaban equivocadas. Se necesita reconocer este hecho para seguir adelante.

Otro evento trágico, en este proceso de desarrollo teológico, fue el reemplazo del principio de sola-tota Scrip- 
tura por el de las fuentes múltiples de la matriz teológica. El adventismo evangélico, entonces, hace teología a partir de la luz hermenéutica que emana de la doctrina de la justificación por la fe. ${ }^{1}$ El adventismo regresivo usa la luz hermenéutica provista por una combinación del evangelio y la ciencia (evolución histórica-biológica). ${ }^{2}$ Estos cam-

${ }^{1}$ Esta es la aproximación hermenéutica seguida por Lutero en la interpretación bíblica y la construcción de las doctrinas cristianas. Jaroslav Pelikan explica, "Lutero podía a veces dar énfasis a la centralidad y la autoridad del Evangelio con una intensidad casi obsesiva, examinando la práctica litúrgica, el precepto ético y aun el dogma teológico mediante este criterio y no así por la norma de conformidad con el significado literal del texto bíblico". Jaroslav Pelikan, The Christian Tradition: A History of the Development of Doctrine, 5 vols. (Chicago: The University of Chicago Press, 1971-1989), 4:181. Esta metodología hace que el principio de sola Scriptura esté subordinado al principio de la justificación por la fe (comprensión de Lutero del evangelio). Stephan Pfürtner concluye tentativamente: "los reformadores, con sus partidarios teológicamente influyentes y sus comunidades, prosiguieron un 'estudio' altamente intensivo del nuevo paradigma, en su marco interpretativo". Stephan Pfürtner, "The Paradigms of Thomas Aquinas and Martin Luther: Did Luther's Message of Justification Mean a Paradigm Change?", en Paradigm Change in Theology, ed. Hans Küng y David Tracy (New York: Crossroad, 1991), 130-160. Véase también Hans Küng, Christianity: Essence, History, and Future, trad. John Bowden (New York: Continuum, 1995), 539-577.

2"El pensamiento teológico adventista debería ser dinámicamente tripolar -es decir, relacionado a tres bases o 'polos', tres asuntos fundamentales que se apoyan y limitan mutuamente el uno al otro en una interacción creativa, espiritual y teológica. En otras palabras, nuestro pensamiento sobre nuestra experiencia, práctica y creencias religiosas debería ser una clase de conversación triangular". Fritz Guy, Thinking Theologically: Adventist Christianity and the Interpretation of Faith (Berrien Springs: Andrews University Press, 1999), 225. Sin dilación, Guy identifica los tres polos que interactúan 
bios paradigmáticos en el nivel macrohermenéutico de la teología adventista producen, a su vez, cambios radicales en la práctica del ministerio, conduciendo a la carismatización del adventismo y a la disposición de estos sectores para unirse espiritualmente al movimiento ecuménico.

Durante el mismo período, los adventistas bíblicos reafirmaron el principio de sola-tota Scriptura ${ }^{3}$ y la doctrina del Santuario, ${ }^{4}$ pero fracasaron al no usarlo como guía hermenéutica para hacer teología y para practicar el ministerio. Los resultados de este cambio paradigmático en el nivel macrohermenéutico de la teología adventista han producido un pluralismo teológico irreconciliable en la teología y práctica adventistas. Este pluralismo no afecta meramente las creencias periféricas o no esenciales, sino a su núcleo y a sus mismos fundamentos. A través de ellos,

mutuamente uno con el otro al moldear nuestra comprensión teológica de lo que creemos. Ellos son, "El evangelio cristiano, que es nuestro centro espiritual; nuestro contexto cultural, que es donde vivimos, adoramos, testificamos y servimos; y nuestra herencia adventista, que es el fundamento de nuestra identidad adventista". Ibíd. La cursiva es del original.

${ }^{3}$ Para una afirmación y explicación del principio de tota Scriptura véase Gerhard Hasel, "The Totality of Scripture versus Modernistic Limitations", Journal of Adventist Theological Studies 2:1 (1991) 30-52, en adelante JATS; Richard M. Davidson, "Biblical Interpretation" en Handbook of Seventhday Adventist Theology, ed. Raoul Dederen, Commentary Reference Series (Hagerstown: Review and Herald, 2000), 60-61.

${ }^{4}$ Para una afirmación de la doctrina del Santuario y soluciones a los temas debatidos véase, por ejemplo, Richard M. Davidson, "In confirmation of the Sanctuary Message", JATS 2:1 (1991) 93-114; William H. Shea, "When did the Seventy Weeks of Daniel 9:24 Begin?" JATS 2:1 (1991) 115-138; C. Mervin Maxwell, "In Confirmation of Prophetic Interpretation", JATS 2:1 (1991) 139-151. 
se extienden a todo el conjunto de creencias y prácticas de la iglesia. Sin embargo, la existencia y la misión de la iglesia requieren unidad en la forma en que se hace y enseña teología en los seminarios, universidades e iglesias alrededor del mundo. Sin unidad de pensamiento, no puede haber comunidad o una misión explosiva. ${ }^{5}$ Debido a que la causa que generó este pluralismo teológico es de naturaleza intelectual, necesitamos superarla intelectualmente.

¿Están en lo correcto, los adventistas evangélicos y progresivos, en cuanto a la honestidad erudita, la búsqueda de la verdad y la forma de alcanzar a las audiencias

${ }^{5}$ Por "unidad" de pensamiento, no me refiero a una comprensión "idéntica" de cada texto, doctrina y práctica. En cambio, me refiero al acuerdo en relación con los principios básicos de la metodología teológica. Deberíamos comprometer nuevamente la teología adventista con el principio de la sola-tota-prima Scriptura del adventismo en sus inicios. A partir de esta base, deberíamos discutir y acordar en cuanto a la forma en que vamos a interpretar los principios macrohermenéuticos de la teología, particularmente, el principio de realidad (ser, Dios, naturaleza humana y el mundo), articulación y conocimiento. La concordancia en la interpretación de estas dos condiciones, a priori del método teológico, es necesaria para la unidad y la coherencia de cualquier programa teológico. Una vez que la comunidad alcanza implícita o explícitamente un acuerdo en estos temas, la investigación teológica producirá puntos de vista diferentes, pero a la vez complementarios y armoniosos entre sí. La diferencia no será causante de disensión, sino que incrementará progresivamente la perfección de nuestra comprensión de la verdad divina. Elena G. de White también vio la variedad como algo esencial para la perfección y se refirió a ella por medio de una breve metáfora: "Hay variedad en un árbol, difícilmente hay dos hojas iguales. Sin embargo, esa variedad acrecienta la perfección del árbol como un todo". Elena G. de White, Mensajes selectos, Vol. 1 (Boise, ID: Pacific Press Publishing Association, 1966), 24. 
seculares posmodernas? ¿Estamos forzados a seguir el ejemplo de los adventistas evangélicos y progresivos para ser honestos intelectualmente? ¿Podemos ser "honestos intelectualmente" mientras todavía hacemos teología a partir de la luz hermenéutica que se irradia a partir de la doctrina del Santuario y la interpretación historicista de la profecía como lo hicieron los pioneros? Si fuera posible, ¿qué deberíamos hacer, a nivel teológico, para ver el sistema completo de teología y verdad que ellos vieron? ¿Qué ocurriría si el rol hermenéutico de la doctrina del Santuario condiciona la metodología teológica? ¿Deberíamos usar un nuevo entendimiento del método teológico ${ }^{6}$, en vez de seguir un método teológico que, supuestamente, es aceptado universalmente? ${ }^{7}$ ¿Existen áreas eruditas que necesitan mayor desarrollo en la teología de la iglesia? ¿Cuáles son

${ }^{6}$ Debido a que Fritz Guy piensa que no hay método teológico adventista, él libremente pide prestado los principios metodológicos de la teología clásica y moderna. El adventismo "no tiene su propia manera separada de pensar teológicamente". Guy, ix. La cursiva está en el original.

${ }^{7}$ El método teológico correlaciona el sistema teológico específico de teología cristiana que sustenta. Cada sistema teológico específico depende de las decisiones concretas que se toman en el nivel fundamental de la metodología teológica. "Las concepciones del método emergen solo en el contexto de una red interrelacionada de creencias. El método no es simplemente un proyecto programático autosuficiente que puede ser fácilmente abstraído del resto de la teología. Por el contrario, las decisiones hechas sobre el método de la teología tanto informan la conceptualización entera del modelo teológico, como así también son ellas mismas informadas por las conclusiones teológicas que emergen a partir de este modelo". Stanley Grenz y John R. Franke, Beyond Foundationalism: Shaping Theology in a Postmodern Context (Louisville: Westminster John Knox, 2001), 12. De este modo, no hay método teológico universal, sino varias metodologías irreconciliables que producen sistemas teológicos irreconciliables. 
las repercusiones de los cambios paradigmáticos en la metodología y el sistema teológico para la unidad y la misión de la iglesia? ¿Es posible alcanzar a la persona contemporánea secularizada dentro y fuera de la comunidad de la iglesia con el mensaje bíblico que resulte intelectualmente atractivo, espiritualmente satisfactorio y vivencialmente gratificante?

\section{Introducción}

Para responder a estas preguntas, necesitamos explorar el rol de la doctrina del Santuario entendida como una visión hermenéutica, a partir de la cual se descubre un sistema completo y armonioso de la verdad en el nivel académico de la investigación científica en los tiempos posmodernos. No obstante, antes de considerar este amplio tema en el próximo artículo (tercer artículo), en este necesitamos dirigir nuestra atención al panorama disciplinario. Esto nos ayudará a comprender dónde estamos ubicados y nos dará una visión general y amplia sobre la tarea que la teología adventista debe emprender. En un cuarto artículo estudiaremos el rol que la teología desempeña en el ministerio y la misión de la iglesia.

¿Por qué fue olvidado, descuidado y reemplazado el uso de la doctrina del Santuario como una visión hermenéutica, a partir de la cual se entendió la Escritura y el sistema completo de verdad en la erudición teológica adventista contemporánea? ${ }^{8}$ Como con todos los eventos

${ }^{8}$ En 1980, Fritz Guy explicó con claridad que la experiencia de los pioneros con la doctrina del Santuario "fue 136 años atrás, en una situación histórica que fue muy diferente de la nuestra. En términos del cambio tecno- 
históricos, debemos asumir que el olvido, descuido y replanteamiento contemporáneo surgen de una variedad de causas. Aquí, quiero explorar brevemente el posible rol que la matriz disciplinaria de la erudición teológica adventista tiene en esta situación. Además, para entender el rol que la visión hermenéutica tiene en la teología erudita, necesitamos considerar el estatus de la matriz disciplinaria en la teología adventista.

Para obtener una comprensión introductoria de la matriz disciplinaria de la teología adventista, bajo la guía hermenéutica de la doctrina del Santuario, seguiré los siguientes pasos. Empezaremos por considerar (1) "el nuevo campo de juego" para la actividad teológica, resaltando algunas características de la investigación teológica erudita que tiene lugar en los seminarios y universidades adventistas. Luego veremos cómo (2) corrientes teológicas diferentes están involucradas en la controversia relacionada con los métodos de la exégesis bíblica histórico-gramatical e histórico-crítica. A continuación, exploraremos (3) los límites de la metodología exegética,

lógico y cultural, estamos tan alejados de 1844 como 1844 lo está del tiempo del Nuevo Testamento. El nuestro es un tiempo de calculadoras electrónicas manuales, comunicación global instantánea (audio con vídeo a todo color) y desajustes horarios causados por largos viajes". Fritz Guy, "Confidence in Salvation: The Meaning of the Sanctuary", Spectrum 11:2 (1980) 44. Él continúa explicando por qué, de acuerdo con él, la comprensión de los pioneros de la doctrina del Santuario se perdió para la generación de Guy. “No hemos experimentado la expectación del Advenimiento de 1844 o su chasco amargo; por más que respetemos a los pioneros adventistas y queramos identificarnos con su experiencia, sigue siendo su experiencia, no la nuestra. Así es que debemos hacernos la pregunta, ¿qué significa la doctrina del Santuario para nosotros hoy, en 1980?", Ibíd. Énfasis añadido. 
y (4) la naturaleza, centro y límites de la teología bíblica. Finalmente, consideraremos la teología sistemática como una disciplina bíblico-teológica.

En medio del pluralismo teológico, los adventismos evangélico, progresivo, histórico y bíblico parecen compartir una presuposición común no expresada y probablemente impensada: tenemos toda la verdad bíblica que necesitamos. Por lo tanto, la mayoría de los adventistas no ven la necesidad del estudio de la Biblia o de la investigación teológica. Los adventistas contemporáneos no ven que el descubrimiento y entendimiento de las verdades bíblicas fomenta la unidad y la misión. Piensan, incorrectamente, que lo que unirá a la iglesia y fomentará su misión es la aplicación de la verdad que ya tenemos en nuestra situación contemporánea. Desgraciadamente, con el tiempo, la "aplicación" se está convirtiendo en "adaptación". La adaptación nos está formando a la imagen del cristianismo protestante carismático.

En este, y el siguiente artículo, me gustaría sugerir que esta presuposición es incorrecta. Por lo tanto, debemos fomentar la necesidad de descubrir y comprender más las verdades bíblicas. En las Escrituras, los pioneros adventistas descubrieron la base hermenéutica para una revolución copernicana en la metodología teológica y el entendimiento de la teología cristiana. Sin embargo, ellos solo comenzaron una revolución que dejaron inconclusa y que, las siguientes generaciones, han dejado de lado por el olvido, el reemplazo y el descuido. Descubrir de nuevo el rol hermenéutico que desempeña la doctrina del Santuario en la metodología teológica y cómo su aplicación nos permite ver el sistema completo de la teología, ayudará al adventismo a superar las divisiones teológicas actuales. Completar la tarea teológica 
que los pioneros dejaron inconclusa, generará unidad en la iglesia mundial y la motivará a involucrarse en la misión final.

\section{El nuevo "campo de juego"}

Cuando la teología adventista se trasladó al entorno universitario, entró en un nuevo "campo de juego", con nuevas reglas para jugar el "juego" teológico. Este campo de juego incluye varias disciplinas teológicas independientes, cada una con su propia metodología, presuposiciones y metas. Estas forman la "matriz disciplinaria" de la teología cristiana erudita. Las disciplinas teológicas, como nosotros las conocemos hoy, se originaron durante el Iluminismo, a mediados del siglo XVIII, cuando la teología bíblica nació como una disciplina independiente. ${ }^{9}$ Sin embargo, podemos rastrear el primer intento para

${ }^{9}$ En el proceso histórico, que dio origen a la teología bíblica como una disciplina independiente, Gerhard Ebeling ve un momento crucial y decisivo que tuvo lugar con la publicación de Gedanken von der Beschaffenheit und dem Vorzug der biblisch-dogmatischen Theologie vor der alten und neuen scholastischen [Reflexiones sobre la naturaleza de la teología dogmática bíblica y su superioridad sobre el antiguo y nuevo escolasticismo] (1758), por Anton Friedrich Büsching, Word and Faith, trad. James W. Leitch (Philadelphia: Fortress, 1963), 87. A través de este paso, la teología bíblica ha pasado de ser una disciplina subsidiaria de la dogmática, a ser "un rival de la dogmática predominante" [Teología escolástica]", ibíd. La teología bíblica "se establece como un estudio completamente independiente, a saber, como una disciplina histórica crítica paralela a la dogmática", en 1787, con una conferencia programática presentada por Johan Philipp Gabler, ibíd, 88; véase también Anthony C. Thiselton, "Biblical Theology and Hermeneutics", in The Modern Theologians: An Introduction to Christian Theology in the Twentieth Century, ed. David F. Ford (Cambridge: Blackwell, 1997), 520. Gerhard Hasel da 
hacer teología bíblica sobre la base del principio de sola Scriptura, a la Reforma Protestante..$^{10}$ Antes de la Reforma, los teólogos interpretaban la Escritura y construían las enseñanzas cristianas siguiendo lo que conocemos hoy como teología sistemática. ${ }^{11}$ Entre las disciplinas involucradas, en la tarea de hacer teología, encontramos a la teología bíblica, la teología sistemática, la práctica del ministerio, la misiología, la ética, la historia de la teología, la historia de la iglesia, la filosofía y un número de ciencias afines, involucradas en la práctica del ministerio y de la misiología. ${ }^{12}$

una fecha ligeramente más temprana para la independencia de la teología bíblica de la dogmática. “Tan temprano como 1745, la 'teología bíblica' está claramente separada de la teología dogmática (sistemática) y la primera se concibe como siendo el fundamento de la última". Gerhard Hasel, Old Testament Theology: Basic Issues in the Current Debate, 2da ed. rev. (Grand Rapids: Eerdmans, 1975), 18.

${ }^{10}$ Ebeling, Word and Faith, 82. "De hecho [explica Ebeling] uno debe decir que la teología de la Reforma es el primer intento, en toda la historia de la teología, de tomar seriamente la demanda por una teología basada solamente en la Santa Escritura". Ibíd. Para una visión general erudita de la teología reformada posterior a la Reforma, véase Richard A. Muller, Prolegomena to Theology (Grand Rapids: Baker, 1987), 251-276.

${ }^{11}$ Así, en los prolegómenos de su Suma teológica, Tomás de Aquino no hablaba acerca de cómo las diversas disciplinas teológicas pueden trabajar juntas, sino acerca de cómo la teología debe relacionarse con la filosofía. Thomas Aquinas, Summa Theologica, trad. Fathers of the English Dominican Province, 3 vols. (New York: Benzinger Brother, 1947). I. 1, 1 y 4.

${ }^{12}$ Ekkehardt Müller describe brevemente la enciclopedia teológica en la educación adventista. "Theological Thinking in the Adventist Church", DavarLogos 1:2 (2002) 128-129. 
Como vimos brevemente en el primer artículo, la teología adventista comenzó como una teología laica. ${ }^{13} \mathrm{El}$ esfuerzo intelectual inicial se ocupó de las disciplinas de la historia ${ }^{14}$ y la cronología. ${ }^{15}$ A principios de su historia intelectual, durante el siglo XX, los eruditos adventistas enfatizaron "la teología bíblica antes que la teología sistemática de los seminarios protestantes generales". ${ }^{16} \mathrm{La}$ teología sistemática fue sospechosa, debido a sus vínculos disciplinarios con los principios filosóficos no bíblicos. En aquel entonces, los adventistas pensaron que este énfasis disciplinario ayudaría a conservar sus creencias y experiencia íntimamente ligada a la Escritura. Podemos entender fácilmente el énfasis colocado en la teología bíblica, si

${ }^{13}$ Esto no significa que ellos no tuvieran un método o no aplicaran un razonamiento cuidadoso para el estudio de las Escrituras. El método de William Miller fue influyente en la temprana teología adventista laica. En pocas palabras, ellos desconfiaron de las interpretaciones tradicionales, adoptaron el principio de sola Scriptura, siguieron una interpretación literal, a menos que el contexto requiriera lo contrario, extrajeron las categorías de interpretación de la Escritura y siguieron la interpretación histórica de la profecía. Para un breve comentario sobre el método de estudio de la Biblia, véase Richard W. Schwarz, Light Bearers to the Remnant denominational History Textbook for Seventh-day Adventist College Classes (Mountain View: Pacific Press, 1979), 32.

${ }^{14}$ En esta área, el trabajo de Le Roy Edwin Froom es notable. Véase su The Conditionalist Faith of our Fathers: The Conflict of the Ages over the Nature and Destiny of Man (Washington: Review and Herald, 1965-66); y Movement of Destiny (Washington: Review and Herald, 1971).

${ }^{15}$ En esta área véase, por ejemplo, Sylvester Bliss, Analysis of Sacred Chronology: With the Elements of Chronology and the Numbers of the Hebrew Test Vindicated (Boston: J. V. Himes, 1851) y Edwin R. Thiele, The Mysterious Numbers of the Hebrew Kings, 3ra ed. (Grand Rapids, MI: Zondervan, 1983).

${ }^{16}$ Richard W. Schwarz, Light Bearers to the Remnant, 489. 
tenemos presente el principio de sola-tota Scriptura sobre el cual la teología adventista se sostiene. ${ }^{17}$ El énfasis disciplinario en la teología bíblica caracteriza a la educación teológica adventista alrededor del mundo hasta el tiempo presente. Los estudios en teología sistemática se convirtieron en meros resúmenes de la enseñanza bíblica.

Para los adventistas, el énfasis en los estudios en Antiguo y Nuevo Testamento resultaba natural. La erudición bíblica parece ser la continuidad y el corolario de su compromiso con el principio de sola-tota Scriptura. La recién descubierta erudición ayudaría al adventismo a confirmar sus creencias generadas por la reflexión "laica" de los pioneros y Elena de White. La nueva forma de estudiar las Escrituras fue la exégesis, "la rama de la teología que investiga y expresa el sentido verdadero de la Sagrada Escritura".${ }^{18}$ La exégesis erudita es "científica" porque se produce a partir de la aplicación del método exegético. ${ }^{19}$ En nuestros días los adventistas realizan su trabajo

\footnotetext{
${ }^{17}$ Véase la creencia fundamental número 1, in General Conference of Seventh-day Adventists, Seventh-day Adventist Believe...: A Biblical Exposition of Fundamental Doctrines (Hagerstown: Review and Herald, 1988), 4.

${ }^{18} \mathrm{~J} . \mathrm{J}$. Maas, "Biblical Exegesis", en New Advent: Catholic Encyclopedia, ed. K. Knight. Disponible en http://www.newadvent.org/ (consultado: 07 abril, 2003). "El término exégesis -explica Moisés Silva- es una forma sofisticada para referirse a la interpretación. Esto significa que la explicación del texto ha involucrado un análisis cuidadoso y detallado. La descripción gramático-histórica indica, por supuesto, que el análisis debe colocar atención tanto al lenguaje en el cual el texto original fue escrito como al contexto cultural específico donde surgió el texto". Walter C. Kaiser y Moisés Silva, An Introduction to Biblical Hermeneutics: The Search for Meaning (Grand Rapids: Zondervan, 1994), 21.
}

${ }^{19}$ Así, Richard Davidson define exégesis como la aplicación de lo que 
erudito usando dos diferentes metodologías exegéticas: el método histórico-gramatical originado por Lutero y la Reforma y el método histórico-crítico, originado por el Iluminismo. ${ }^{20}$ Los adventistas bíblicos siguen el método histórico-gramatical, mientras los adventistas progresivos adoptaron una "versión modificada" del método histórico-crítico. ${ }^{21}$

él llama el "método hermenéutico histórico-bíblico". Exégesis, entonces, es "el intento de entender el significado de los datos bíblicos, usando consideraciones metodológicas originadas a partir de la Escritura solamente". Davidson, "Biblical Interpretation", 94.

${ }^{20}$ Gerhard F. Hasel, Biblical Interpretation Today (Washington: Biblical Research Institute, 1985), 3-6.

${ }^{21}$ Jerry Gladson, “Taming Historical Criticism: Adventist Biblical Scholarship in the Land of the Giants", Spectrum (April 1988): 19-34. Como un resultado de esta afirmación, "tenemos entre los adventistas hoy más o menos dos hermenéuticas, una es la aproximación histórica adventista del séptimo día con menores modificaciones, la otra es una hermenéutica basada en diferencias sustancialmente fundacionales, como hemos descrito arriba. Esta última involucra modalidades prominentes en el criticismo histórico (o el método histórico-crítico) pero que afirma haber purgado sus más obvias presuposiciones humanísticas, tal como la negación de lo sobrenatural"., George W. Reid, "Another Look at Adventist Hermeneutics", JATS 2:1 (1991) 72. Gladson argumenta que deberíamos aceptar el desarrollo histórico-dinámico del criticismo histórico y rechazar sus suposiciones naturalistas. Gladson, 22. Esta propuesta, sin embargo, opera sobre premisas imaginarias. El criticismo histórico, en la teología bíblica, siempre ha aceptado la trascendencia divina. La trascendencia, sin embargo, pertenece al ámbito espiritual atemporal, no al ámbito histórico donde el criticismo histórico reescribe la historia bíblica, despojándola de las acciones divinas en las secuencias históricas en el tiempo. Para un cuidadoso estudio del desarrollo del método histórico-crítico, su dependencia de categorías filosóficas y la manera cómo acomoda la trascendencia divina mientras reescribe la histo- 
Durante los últimos sesenta años, los estudios bíblicos se han desarrollado extensivamente a través del adventismo bíblico. Los exégetas, usando principalmente el método histórico-gramatical de la Reforma, han examinado cuidadosamente los textos bíblicos a partir de los cuales los pioneros derivaron los pilares adventistas y la visión del Santuario. Gracias a este continuo esfuerzo, de investigación cuidadosa, sabemos que estas doctrinas se erigen sobre un fundamento bíblico sólido y tienen significados más enriquecedores y más profundos que lo que las generaciones previas entendieron. ${ }^{22}$

ria, véase Raúl Kerbs, "El método histórico-crítico en teología: En busca de su estructura básica y de las interpretaciones filosóficas subyacentes (parte I)”, DavarLogos 1:2 (2002) 105-123; Raúl Kerbs, “El método histórico-crítico en teología: En busca de su estructura básica y de las interpretaciones filosóficas subyacentes (parte II), DavarLogos 2:1 (2003) 11-27. George Reid correctamente observa: "El punto crucial de la cuestión es si una mezcla de la aproximación adventista histórica con el criticismo histórico es posible. Algunos sostienen la opinión de que mucho, en el criticismo histórico, es de ayuda en la exégesis y la teología. En última instancia, mucho de esto depende de si la crítica histórica es en verdad un sistema o si es un simple conjunto de técnicas esporádicas a las que se puede recurrir pragmáticamente según la utilidad individual". Reid, "Another Look at Adventist Hermeneutics", 73. Desafortunadamente, el método no puede ser un conjunto aislado de técnicas. Incluso afirmando la trascendencia, la propuesta de Gladson todavía se encuentra sobre los fundamentos filosóficos de la crítica histórica.

${ }^{22}$ Véase, por ejemplo, el diálogo erudito sobre la interpretación del velo en el Santuario celestial, de acuerdo al libro de Hebreos. Davidson presenta la visión del adventismo bíblico en respuesta al argumento de Young a partir de la perspectiva adventista evangélica. Roy E. Gane, "Reopening Katapetasma ('veil') in Hebrews 6:19", Andrews University Seminary Studies 38:1 (2000) 5-8, en adelante AUSS; Norman H. Young, "'Where Jesus has Gone as Forerunner on our Behalf' (Hebrews 6:20)", AUSS 39:2 (2001) 165-173; Richard Davidson, 


\section{El punto decisivo}

La historia es esencial, no solamente para el entendimiento de la profecía, sino también para la comprensión de las enseñanzas cristianas. En la interpretación profética, los adventistas bíblicos e históricos todavía trabajan dentro de una tradición interpretativa historicista. ${ }^{23}$ Teológicamente, los adventistas también piensan históricamente desde el interior de la dinámica del Gran Conflicto. Ambas tendencias asumen la presencia histórica real de Dios actuando directamente dentro del flujo espacio-temporal de la historia humana. Como veremos en el siguiente artículo, en ambos campos, la teología adventista no tiene igual. Ninguna otra tradición o escuela de teología cristiana comparte la visión adventista sobre la interpretación profética y la matriz del Gran Conflicto para la teología sistemática. ¿Por qué esto es así? ¿Hay razones metodológicas detrás de este enfoque único en la teología cristiana?

El método histórico-gramatical. Exegéticamente, el adventismo bíblico opera con el método histórico-gramatical. Al aplicarlo se da por sentado que la Escritura habla

“Christ's Entry 'Within the Veil' en Hebrews 6:19-20: The Old Testament Background", AUSS 39:2 (2001) 175-190; Norman H. Young, “The Day of Dedication or the Day of Atonement?: The Old Testament Background to Hebrews 6:1920", AUSS 40:1 (2002) 61-68; Richard Davidson, "Inauguration or Day of Atonement? A Response to Norman Young's Old Testament Background to Hebrews 6:19-20 Revisited", AUSS 40:1 (2002) 69-88.

${ }^{23}$ Jon Paulien, "The End of Historicism?: Reflections on the Adventist Approach to Biblical Apocalyptic-Part One", JATS 14:2 (2003) 15-42; véase también Reimar Vetne, "A Definition and Short History of Historicism as a Method for Interpreting Daniel and Revelation", JATS 14:2 (2003) 1-14. 
sobre eventos históricos reales en el espacio y el tiempo. Los procedimientos involucrados en el método históricogramatical ayudan a determinar el significado de los textos bíblicos más bien que a establecer la realidad histórica de sus referentes. En general, los exégetas conservadores asumen que la Escritura describe los eventos históricos como realmente sucedieron en la historia. Por lo tanto, el método histórico-gramatical fue útil en establecer el significado de los eventos bíblicos; sin embargo no ayudó mucho en el campo teológico. El método teológico ha complementado al exegético al explicar en qué sentido las acciones de un Dios atemporal, no histórico y espiritual son reales. En un sentido implícito, entonces, el método histórico-gramatical era incompleto y se encontraba abierto a la corrección de la reflexión teológica y filosófica. Debido a los límites de la exégesis (véase la sección 5), el método histórico-gramatical no es suficiente para fundamentar la interpretación historicista de la profecía y el enfoque del Gran Conflicto en la teología sistemática. Esta limitación metodológica puede ser uno de los factores que contribuyeron al surgimiento del adventismo evangélico.

El método histórico-crítico. Con el advenimiento de la modernidad y la conciencia histórica, los exégetas adoptaron el método histórico-crítico de interpretación bíblica. ${ }^{24}$ La modernidad generó cambios paradigmáticos en la epistemología que, a su vez, produjeron una nueva forma de estudiar los eventos históricos. Superficialmen-

${ }^{24}$ He encontrado en Steve MacKenzie y Stehen Haynes, ed., To Each Its Own Meaning: An Introduction to Biblical Criticisms and their Application (Louisville: John Knox, 1999) una introducción muy útil y completa a la compleja matriz de las metodologías de la exégesis histórico-crítica. 
te, el énfasis moderno en la historia parece afirmar el enfoque historicista a la interpretación profética, la interpretación de la Biblia y a la teología sistemática que opera en el adventismo.

¿Es la metodología histórico-crítica compatible con el pensamiento bíblico y la teología adventista? ¿Deberían los adventistas usar el método histórico-crítico o evitar sus conclusiones y criticar sus operaciones epistemológicamente?25 En pocas palabras, podemos decir que la aplicación del método histórico-crítico lleva a una reinterpretación de lo que realmente ocurrió en la historia, negando los milagros y todo lo sobrenatural. Por lo tanto, la teología adventista no puede usar este método sin sacrificar el principio de sola-tota Scriptura y el sistema completo de teología y verdad que la visión hermenéutica del Santuario permitió visualizar. ${ }^{26}$ Recordemos que el método histórico-crítico reinterpretó no solo la "Historia de Israel" sino también los actos salvíficos de Dios en el Antiguo y el Nuevo Testamento. Como resultado, existen paralelamente dos versiones diferentes de la misma historia: la versión "científica" de lo que "realmente sucedió" generada a partir de la aplicación del método históricocrítico a la historia bíblica, y la versión bíblica de lo que

${ }^{25}$ Para una respuesta negativa, véase Edward Zinke, Historical Criticism, Biblical Research Institute, 1981. Disponible en http://biblicalresearch.gc.adventist.org/documents/historicalcriticism.htm (consultado el 07 de abril, 2014); para una respuesta positiva, véase Gladson.

${ }^{26}$ Para un tratamiento crítico del método histórico-crítico véase, por ejemplo, Gerhard Maier, The End of the Historical Critical Method, trad. Edwin W. Leverenz and Rudolph F. Norden (St Louis: Concordia, 1977); y Eta Linnemann, Historical Criticism of the Bible: Methodology or Ideology, trad. Robert W. Yarbrough (Grand Rapids: Baker, 1990). 
"realmente sucedió" generada a partir de la perspectiva de la experiencia diaria común de la historia, debido a que la historia de la Biblia presenta a Dios actuando dentro del flujo de la historia como un agente entre otros, la ciencia no puede aceptar esto como verdadero, sino solo como un producto mitológico de la imaginación religiosa. ${ }^{27}$ De hecho, el nacimiento de las ciencias empíricas desencadenó la reinterpretación moderna del cristianismo que alcanza

${ }^{27}$ Respondiendo a una acusación de que su posición implica relativismo, Ernst Troeltsch explica que no está hablando de un proceso "inmanente en toda la historia humana". Ernst Troeltsch, Religion in History, trad. James Luther Adams and Walter F. Bense (Minneapolis: Fortress, 1991), 67. En el proceso evolutivo de la historia, argumenta Troeltsch, cada momento tiene "una relación directa con Dios que pertenece solo a este. Ellos son temporalmente discretos $\mathrm{y}$, sin embargo, también aproximaciones a la vida Absoluta". Ibíd. A partir de este fundamento metafísico "objetivo" y no histórico, "el pensamiento religioso se desarrolla en la manera que le es distintiva. En la medida en que se vale de cada recurso de estimulación y expresión, el pensamiento religioso se asemeja más a la imaginación artística $y$, sin embargo, es todavía distinta de esta por la experiencia de una realidad sobrehumana irresistible, revelándose a sí misma en todas partes. Cada expresión es mítica, simbólica, poética; sin embargo, en la expresión se capta algo que lleva dentro de sí mismo, en una manera específicamente religiosa, su propia necesidad interior y su poder irresistible". Ibíd., 57. De esta manera, se origina el lenguaje religioso. De este modo, se origina la Escritura. Es claro que el criticismo histórico de Troeltsch para la investigación bíblica y la religionsgeshichtliche Methode (metodología de las religiones) no es "naturalista". Es decir, tiene en cuenta las presuposiciones "trascendentes" que Gladson requiere como condiciones necesarias para una apropiación adventista del método histórico-crítico. Obviamente, necesitamos más que las sugerencias de Gladson para que podamos usar el método histórico-crítico únicamente por asumir la "trascendencia" en lugar del "naturalismo" de Troeltsch. Gladson, 27. 
el fundamento, la metodología y el sistema de la teología cristiana. A partir de la perspectiva científica, las Escrituras son mitos generados por la imaginación humana catalogados bajo el rótulo de Heilsgeschichte (historia de la salvación). ${ }^{28}$ No debemos ignorar que, de hecho, la crítica histórica sigue una comprensión estricta de la realidad que nos impide aceptar el registro bíblico de la historia que presenta a Dios actuando "realmente" en la secuencia espacio-temporal de los seres humanos. Sin embargo, ¿es absoluta la visión científica de la realidad? ¿Existe otra interpretación de la realidad que pueda fundamentar la factibilidad histórica de la Heilschehichte bíblica? Retornaremos a estas preguntas en el siguiente artículo.

En lugar de explorar estas posibilidades en las áreas de la ontología y la epistemología, los adventistas progresivos argumentan en favor de una versión "modificada" del método histórico-crítico. Jerry Gladson sugiere que "los eruditos bíblicos adventistas deberían hacer uso de una versión modificada del criticismo histórico, con tal que no quiten el nivel trascendente o desafíen la autoridad teológica y la inspiración de las Escrituras". ${ }^{29}$ Su sugerencia, sin embargo, falla al menos en dos sentidos. Primero,

${ }^{28}$ Describiendo la forma en que la dogmática tradicional trata con la historia, Troeltsch explica: "el método dogmático también pretende basarse sobre la 'historia'. Pero esta no es la historia ordinaria, secular, reconstruida por la historiografía crítica. Es más bien una historia de la salvación (Heilsgeschichte), un nexo de los hechos salvíficos que, como tales, pueden conocerse y comprobarse solo por los creyentes. Estos hechos, precisamente, tienen las características opuestas de los hechos que los historiadores seculares y críticos pueden considerar, sobre la base de sus criterios, como habiendo realmente sucedido", ibíd, 21.

${ }^{29}$ Gladson, 27. 
la interpretación de Ernst Troeltsch de la metodología histórico-crítica no construye sobre presuposiciones naturalistas sino que asume la trascendencia divina. ${ }^{30}$ Segundo, hay varias maneras para interpretar la inspiración de la Biblia. Por ejemplo, Paul J. Achtemeier sugiere que la inspiración del Espíritu Santo no actuó en los autores individuales sino sobre la comunidad, siguiendo el proceso evolutivo descrito por los eruditos históricos críticos. ${ }^{31}$ De acuerdo a su opinión, la "inspiración" se refiere a la conducción del Espíritu Santo en la comunidad, cuando esta dio forma a los contenidos de la Escritura y formuló sus escritos. ${ }^{32}$ Por lo tanto, el método histórico-crítico puede funcionar, asumiendo la trascendencia de Dios y la inspiración de las Escrituras, sin requerir ninguna modificación sustancial.

Aunque Gladson hace algunas observaciones acertadas acerca de los usos ad hoc en aspectos periféricos del criticismo histórico por algunos escritores adventistas, él no logra explicar, con fundamento erudito, las diferencias

${ }^{30}$ Troeltsch construye sobre el trascendentalismo de Kant y el registro de la revelación del encuentro de Schleiermacher. Él habla de un apriorismo “irracional" en la razón humana. Hay "una concentración de la conciencia religiosa sobre esto mismo en virtud de los elementos objetivo-religiosos incluidos en la subjetividad. Troeltsch, Religion in History, 59. Más tarde, él identifica el apriorismo "irracional" en la razón humana con Dios. "El presente [afirma Troeltsch] es completamente llenado por la cercanía inmediata de Dios", ibíd, 66.

${ }^{31} \mathrm{El}$ pensamiento evolutivo de Hegel juega un rol estructural en la interpretación de la gestación de la Escritura, de acuerdo a la matriz del método histórico-crítico. Troeltsch, Religion in History, 59.

${ }^{32}$ Paul J. Achtemeier, Inspiration and Authority: Nature and Function of Christian Scripture (Peabody: Hendrickson, 1999), 118-121. 
entre la versión adventista modificada que él visualiza y la práctica académica real de la crítica histórica en la erudición contemporánea. Al no lograr definir claramente su posición metodológica ni percibir la presuposición atemporal desde la cual se critica la historia bíblica, los eruditos adventistas que adoptan una "versión modificada" del método histórico-crítico inevitablemente arribarán a conclusiones que distorsionarán el pensamiento bíblico. En consecuencia, rechazarán el flujo de las acciones históricas de Dios, y argumentarán en contra de la dinámica de la Gran Controversia que caracteriza la teología adventista. Como expliqué anteriormente, la aplicación del criticismo histórico a la interpretación de la Escritura y la comprensión de las doctrinas cristianas requieren cambios paradigmáticos ${ }^{33}$ no solo en la comprensión de la inspiración de la Escritura y el principio de sola Scriptura que fundamentan el pensamiento teológico adventista, sino también en la interpretación del ser de Dios y su accionar histórico, asumidos en la visión hermenéutica de la doctrina del Santuario.

En busca de un método alternativo. Es necesario distinguir entre el criticismo histórico propiamente dicho y el criticismo histórico como un título amplio y abarcante. El primero se refiere a la crítica histórica de

${ }^{33}$ "Dé al método histórico una pulgada y tomará una milla. Desde un punto de vista estrictamente ortodoxo, por lo tanto, parece admitir una cierta similitud con el diablo. Al igual que las ciencias naturales modernas, esto representa una revolución completa en nuestros patrones de pensamiento, con relación a la antigüedad y a la Edad Media. Como estas ciencias implican una nueva actitud hacia la naturaleza, así la historia implica una nueva actitud hacia el espíritu humano y sus producciones en el ámbito de las ideas". Ernest Troeltsch, Religion in History, 16. Énfasis añadido. 
los eventos descritos en la Escritura, con el propósito de verificar su realidad histórica. ${ }^{34} \mathrm{El}$ segundo se convierte en la etiqueta que congrega una variedad de estudios relacionados de los textos bíblicos, donde todos asumen los resultados del método histórico-crítico propiamente dicho. En su sentido amplio, el método histórico-crítico incluye una multiplicidad con componentes o investigaciones interrelacionadas de la Escritura que usualmente se conocen como "criticismo". Entre ellos encontramos, por ejemplo, el criticismo histórico propiamente dicho $\mathrm{y}$, edificado sobre este, la crítica de las fuentes, de las formas, de la tradición, de la redacción, crítica socialcientífica, canónica, retórica, estructural, narrativa, crítica de la respuesta del lector, crítica posestructuralista, feminista, y socioeconómica. ${ }^{35} \mathrm{Al}$ menos teóricamente, esta distinción nos permite vislumbrar la posibilidad de que las críticas enunciadas anteriormente, en el sentido amplio del método histórico-crítico, puedan arrojar resultados diferentes si las aplicamos sin asumir los resultados del método-histórico propiamente dicho. Lo que el adventismo bíblico encuentra objetable y no científico ${ }^{36}$ es el método histórico-crítico propiamente dicho

${ }^{34}$ "Los historiadores buscan objetividad. Ellos están interesados en descubrir y reportar lo que realmente sucedió en el pasado, en lugar de coleccionar y transmitir historias de ensueño, escribiendo 'docudramas', o produciendo registros revisionistas del pasado por propósitos propagandistas o ideológicos". Mackenzie y Haynes, 18.

${ }^{35}$ Véase la tabla de contenido de Mackenzie y Haynes.

${ }^{36}$ Ian W. Provan correctamente explica que el modelo historiográfico científico moderno, que aplica el método histórico-crítico de la investigación bíblica, ha colapsado. Ian W. Provan, "Knowing and Believing: Faith in the Pas- 
y su abierta enemistad contra la realidad histórica de los eventos bíblicos que describen las acciones de Dios dentro de la historia humana.

Si los exégetas adventistas siguen tratando de resolver la cuestión metodológica, eligiendo entre los métodos histórico-gramatical e histórico-crítico, las divisiones que existen en el adventismo se multiplicarán y se fortalecerán. Sin embargo, nos preguntamos, ¿son estas las únicas alternativas posibles? ¿Pueden los pensadores adventistas abordar la cuestión metodológica críticamente, buscando fundamentar, articular y formular una nueva metodología exegética? La finalización de la tarea inconclusa de la teología adventista requiere repensar el tema de la metodología exegética. Necesitamos encontrar una nueva alternativa metodológica que incluya todas las características de los textos bíblicos. La superación del pluralismo teológico, que existe en la iglesia, requiere una tarea de deconstrucción, a través de la crítica episte-

to", en "Behind" the Text: History and Biblical Interpetation, ed. Craig Bartholomew et al. (Grand Rapids: Zondervan, 2003), 244. Por lo tanto, sus modelos, presuposiciones y procedimientos ya no se pueden tomar seriamente. Desafortunadamente, los eruditos bíblicos continúan construyendo sobre la visión metodológica que la historiografía posmoderna ha criticado y abandonado. Por lo tanto, ¿qué es lo que se viene en la historiografía? Provan correctamente interpreta "la crisis con relación al modelo científico de historiografía -y ciertamente la contraproducente respuesta posmodernista a esta crisis- como una invitación a retomar algunas cuestiones fundamentales con relación a la epistemología". Ibíd. En otras palabras, uno tiene que sospechar que los problemas en el modelo historiográfico científico moderno provienen de errores en el amplio nivel de las presuposiciones epistemológicas y ontológicas. Necesitamos reconsiderar nuestra comprensión sobre estos temas y, a partir de ellos, generar un mejor modelo historiográfico científico que podamos aplicar al estudio de la historia en general y a la historia bíblica en particular. 
mológica. Cuando terminemos la crítica deconstructiva, necesitamos involucrarnos en la tarea constructiva de fundamentar e idear un nuevo método histórico-científico de interpretación bíblica. ${ }^{37}$

Sin embargo, ¿cómo hacemos esto? ¿Cómo estudiamos y producimos metodologías exegéticas? ¿Existe una disciplina teológica donde podamos analizar, criticar y formular nuevas aproximaciones metodológicas? Como veremos más adelante, para tratar seriamente con el tema metodológico, la teología adventista necesita entrar en un nuevo campo académico. Para estudiar el estatus académico de la teología, sus metodologías, las disciplinas requeridas para procesar sus datos y alcanzar sus objetivos, la relación interdisciplinaria interna y externa, el origen del conocimiento teológico y la estructura general de la interpretación, necesitamos involucrarnos en la teología fundamental.

La cuestión es: ¿por qué algunos eruditos adventistas están tan convencidos de que deberíamos usar el método histórico-crítico en la teología adventista, mientras otros están convencidos de lo contrario y con la misma pasión? La respuesta a esta pregunta no es simple. Parte de ella gira alrededor de las presuposiciones teológicas y las preconcepciones filosóficas que, implícita o explícitamente, traemos a la tarea de la exégesis. Antes de considerarlas, necesitamos reconocer los límites de la metodología bíblica y de la teología bíblica.

${ }^{37}$ Tal vez esto es lo que Gerhard Hasel y Richard Davidson tenían en mente cuando hablaron, respectivamente, de un "método teológico-bíblico" y un "método "histórico-bíblico". Véase Hasel, Biblical Interpretation Today, 113; Davidson, "Biblical Interpretation", 94. 


\section{Los limites de la exégesis}

Aunque la aplicación exegética del método histórico-gramatical y el desarrollo de la teología bíblica han fortalecido al adventismo bíblico, su modus operandi no tiene espacio para una aplicación consistente de la doctrina del Santuario como una visión paradigmática a partir de la cual los pioneros adventistas descubrieron el sistema completo de teología y de verdad presente en la Escritura. Entender estas limitaciones metodológicas y disciplinarias de la erudición exegética puede ayudarnos a apreciar con más detalle el olvido de la visión adventista y su sistema de teología entre los adventistas bíblicos. A medida que nuestras limitaciones metodológicas y disciplinarias preprogramadas se hagan visibles, podremos esbozar la tarea que queda por delante: finalizar la obra inconclusa de la teología adventista y superar el pluralismo y estancamiento actual del pensamiento y misión de la iglesia.

Preferiría que alguno de mis estimados colegas exégetas investigara sobre los límites de la teología bíblica. Yo sé que este es un asunto delicado para muchos involucrados en la teología adventista. La razón es sencilla. En mi limitada experiencia personal no he escuchado a exégetas adventistas sugerir que necesitan el apoyo, complementación y corrección de otras disciplinas teológicas, tales como la teología sistemática o la teología fundamental. Mis colegas exégetas y estudiantes deberían darse cuenta de que esta propuesta no intenta desafiar, sino complementar y reforzar lo que ellos ya están haciendo. Algunos años atrás, después de hablar sobre los límites de la exégesis bíblica en el club doctoral del Seminario Teológico Adventista del Séptimo Día, en Andrews University, un grupo de estudiantes de Antiguo y Nuevo Testamento 
encontró que el solo pensar en los límites de la exégesis los hacía sentirse amenazados. Ellos no me explicaron la razón por la cual pensaban de esta manera. Me imagino que su reacción puede haber estado vinculada en cierta forma con el miedo a lo desconocido.

El adventismo bíblico básicamente identifica la metodología exegética con la metodología teológica. Esta mentalidad disciplinaria implícitamente asume que solo podemos hacer teología exegéticamente. Por la aplicación de una rigurosa metodología exegética a los textos bíblicos, descubrimos la verdad y la aplicamos a nuestra situación presente. En pocas palabras, para descubrir la verdad bíblica solo necesitamos la metodología exegética. En consecuencia, los adventistas bíblicos están convencidos de que, para descubrir la verdad bíblica, no necesitamos disciplinas tales como la teología sistemática y la fundamental. En el mejor de los casos, piensan que la teología sistemática puede ser útil en presentar, en una forma ordenada, los resultados que la teología bíblica alcanza mediante la metodología exegética. ${ }^{38}$ Pero, en general, piensan que debemos evitarlas, ya que pueden dañar nuestro intento de construir fielmente nuestra teología sobre el principio de sola Scriptura y la guía hermenéuti-

${ }^{38} \mathrm{Si}$ una tradición decide construir la teología cristiana sobre el principio de sola-tota Scriptura, uno se pregunta sobre el papel de la teología sistemática. Si la teología bíblica no solo descubre lo que los escritores bíblicos quisieron decir allá por sus días, sino también decide lo que el texto significa para nosotros hoy y nos presenta un informe completo de la interconexión de la teología del Antiguo y Nuevo Testamento, ¿habría alguna necesidad de teología sistemática? La respuesta parece ser no. En relación a esto, véase mi "Is there Room for Systematics in Adventist Theology", JATS 12:2 (2001) 110-131. 
ca de la doctrina del Santuario. Personalmente entiendo que hay muchas razones para sospechar de la teología sistemática y de la teología fundamental que edificaron sobre la matriz teológica de las fuentes múltiples. Esta sospecha no debería disminuir en el adventismo. Al contrario, debería motivar un intensivo proyecto de deconstrucción teológica.

Aquí, sin embargo, necesitamos concentrarnos en las limitaciones de la exégesis bíblica, convocando a las metodologías disciplinarias complementarias para que se unan a la exégesis en la búsqueda de la verdad bíblica. Para nuestros propósitos, en este artículo, solo necesitamos considerar brevemente dos limitaciones. Una viene del lado de las presuposiciones hermenéuticas y la otra del lado de los datos y objetos del método exegético.

Presuposiciones. Necesitamos tener en cuenta que el método es un camino que seguimos para lograr algunas metas. ${ }^{39}$ Bernard Lonergan correctamente describe al método como "un patrón normativo de operaciones recurrentes y relacionadas que producen resultados acumulativos y progresivos". ${ }^{40}$ En un sentido técnico, el método es un con-

${ }^{39}$ Fernando Canale, “Evolution, Theology and Method Part I: Outline and Limits of Scientific Methodology", AUSS 42:1 (2003) 65-100; 70-71.

${ }^{40}$ Bernard Lonergan, Method in Theology (Toronto: U of Toronto P, 1990), 5. Lonergan explica, además, que "hay método, entonces, donde hay operaciones distintas, donde cada operación está relacionada con otras, donde el conjunto de relaciones forma un patrón, donde el patrón se describe como el camino correcto para hacer el trabajo, donde las operaciones en concordancia con el patrón pueden ser repetidas indefinidamente, y donde los frutos de cada repetición son, no repetitivos, sino acumulativos y progresivos". Ibíd., 4. En consecuencia Lonergan organiza su discurso sobre el método como una identificación y explicación de las 
junto de procedimientos o reglas prescritas, con el propósito de facilitar el logro de una meta ${ }^{41}$ Así como el método científico, el método teológico también tiene condiciones que regulan sus actividades, procedimientos y operaciones. Además de las (1) metas concretas que se pretenden alcanzar, el método teológico también requiere (2) datos, (3) las necesarias presuposiciones hermenéuticas y los criterios para procesar los datos y alcanzar sus metas. Las metas son asuntos que requieren interpretación y explicación teológicas. Los datos son la información acerca de Dios que necesitamos para descubrir los temas que requieren explicación. Las necesarias presuposiciones hermenéuticas son los principios que guían la interpretación y la construcción teológica. ${ }^{42}$ En resumen, los objetivos del método son su condición teleológica, los datos son su

operaciones involucradas en la tarea de hacer teología. Ibíd., 6-25. John Macquarrie concuerda con la definición de Lonergan sobre el método, pero procede a aplicarlo de una manera diferente a la tarea de la teología. John Macquarrie, Principles of Christian Theology, 2da ed. (New York: Charles Scribner's Sons, 1977), 33.

${ }^{41}$ René Descartes explica que "por método me refiero a reglas sencillas y precisas, de modo que, si un hombre las observa con precisión, nunca asumirá lo que es falso como verdadero, y nunca gastará sus esfuerzos mentales para ningún propósito, sino que siempre incrementará gradualmente su conocimiento y así llegará a una verdadera comprensión de todo lo que no supera sus poderes". René Descartes, "Rules for the Direction of the Mind", in Great Books of the Western World, ed. Robert Maynard Hutchins (Chicago: Encyclopaedia Britanica, 1952), 5.

${ }^{42}$ Por "construcción" me refiero al procedimiento por el cual arribamos a conclusiones y enseñanzas a través de la conexión de textos e ideas. Esto toma lugar en la exégesis, pero se da en un grado mayor en la teología bíblica y en la sistemática. 
condición material, y los principios de interpretación que asumen son su condición hermenéutica. Todas las condiciones en estrecha interacción conforman los perfiles concretos de los métodos teológico y científico. ${ }^{43}$

Los datos en la exégesis bíblica son los textos del Antiguo y Nuevo Testamento. La meta es entenderlos. Sin embargo, ¿de dónde vienen las condiciones hermenéuticas o las presuposiciones? Algunos años atrás, una declaración oficial de la Asociación General de los Adventistas del Séptimo Día, en su Concilio Anual, abordó el tema del estudio de la Biblia identificando algunas de las presuposiciones que llevamos a la tarea de la interpretación bíblica y que, por tanto, forman parte de nuestro método de estudio bíblico. ${ }^{44}$ Este documento afirma que (1) la inspiración divina de la Escritura, (2) su autoridad sobre la razón, y (3) el rol del Espíritu Santo son presuposiciones necesarias derivadas de la Escritura. El documento solo enumera y esboza el contenido de estas presuposiciones básicas, sin explicar cómo sabemos que son presuposiciones y cómo descubrimos sus contenidos.

De esta manera, las limitaciones de la metodología exegética y de los estudios exegéticos se tornan evidentes porque ambas requieren la identificación y la interpreta-

${ }^{43}$ Para clarificación adicional, con relación a las condiciones del método teológico, véase mi "Interdisciplinary Method in Christian Theology? In Search of a Working Proposal", Neue Zeitschrift für Systematische Theologie und Religionsphilosophie 43:3 (2001) 371-375; y Kwabena Donkor, Tradition, Method, and contemporary Protestant Theology: An analysis of Thomas C. Oden's Vincentian Method (Lanham: U P of America, 2003), 43-74.

${ }^{44}$ General Conference Committee Annual Council, "Methods of Bible Study: Presuppositions, Principles and Methods" (Río de Janeiro: Biblical Research Institute, 1986). 
ción de algunas nociones amplias e influyentes que asumen los exégetas. Ya que el objetivo del método exegético es la comprensión de los textos bíblicos, y los tales no abordan la discusión del método o sus presuposiciones, es obvio que dependen de las reflexiones no-exegéticas que se originan en el nivel hermenéutico fundamental. Debido a que los exégetas y los teólogos tradicionalmente han derivado sus presuposiciones hermenéuticas de la filosofía, la declaración de la Asociación General sobre "Métodos de estudio de la Biblia", aconseja a los eruditos adventistas que deriven sus presuposiciones de la Escritura misma. ${ }^{45}$ Debería haber una manera erudita, entonces, para analizar, discutir, descubrir, describir y decidir qué presuposiciones son necesarias para la exégesis bíblica y cómo deberíamos entenderlas sobre la base del principio de sola Scriptura. ${ }^{46}$ Esta tarea requiere el involucramiento de una disciplina teológica diferente, esto es, la teología fundamental. Volveremos a este asunto en el siguiente artículo.

Textualidad. Consideremos la limitación que aparece del lado del objetivo de la exégesis, es decir, de la comprensión del texto. Uno de los procedimientos metodológicos que la exégesis debe seguir deriva de la naturaleza

\footnotetext{
${ }^{45}$ Véase pie de página 45.
}

${ }^{46}$ Gerhard Hasel indica correctamente que, en la teología adventista, "las presuposiciones deben estar constantemente abiertas a la modificación y ampliación sobre la base de la Escritura. Cualquier precomprensión que está vinculada a conceptos tales como el naturalismo, con su universo cerrado de una red de causa y efecto inmanente, al evolucionismo con sus axiomas de desarrollo o al cientificismo, humanismo, racionalismo o relativismo es ajeno a la Biblia. La Palabra de Dios no debe ser forzada a adaptarse a tales conceptos extraños o a sus presuposiciones". Hasel, Biblical Interpretation Today, 104. 
de sus datos, los textos bíblicos. Los métodos históricogramatical e histórico-crítico están de acuerdo en que los textos fluyen desde dentro de una matriz histórica. Por lo tanto, la determinación del contexto histórico ofrece un marco de referencia fundamental para la comprensión de todos los textos bíblicos. ${ }^{47}$ El carácter histórico de la escritura bíblica prohíbe a los exégetas interpretar cualquier texto bíblico sobre la base de las ideas que se encuentran en textos bíblicos posteriores. El exégeta debe tratar de interpretar el texto desde las perspectivas ideológicas del autor y de la audiencia original. Esto muestra otra limitación de la metodología exegética. Nunca seremos capaces de reconstruir el contexto histórico completo. La exégesis siempre produce una comprensión parcial de los textos. Por ejemplo, la metodología exegética no nos permite usar el conflicto cósmico presentado en Apocalipsis 12:7-9 como un contexto histórico para Génesis 1:3. ${ }^{48} \mathrm{Sin}$

${ }^{47}$ Davidson, "Biblical Interpretation", 70-74.

${ }^{48}$ Es cierto que los eruditos del Antiguo Testamento no pueden ignorar completamente la existencia del Nuevo Testamento, cuando interpretan el Antiguo Testamento. Gerhard F. Hasel, "Proposals for a Canonical Biblical Theology", AUSS 34: 1 (1995) 25-26. Los eruditos del Antiguo Testamento no pueden usar la teología del Nuevo Testamento y los datos como presuposiciones hermenéuticas para encontrar el significado histórico-teológico del texto del Antiguo Testamento. Los teólogos bíblicos, sin embargo, pueden usar los motivos, tipos y teología del Antiguo Testamento para determinar el significado de los pasajes del Nuevo Testamento. Por ejemplo, Richard Davidson usa convincentemente la ceremonia de la inauguración del Santuario del Antiguo Testamento para determinar el significado de la entrada de Cristo al Santuario celestial después de su resurrección como se presenta en Hebreos 6:19-20. Davidson, "Christ's Entry 'Within the Veil' in Hebrews 6:19-20: The Old Testament Background," 175-190; Davidson, "Inaugura- 
embargo, la teología adventista trabaja dentro de la dinámica de la Gran Controversia. Se entiende la Escritura y la salvación en el contexto del conflicto cósmico que precede a la creación de nuestro planeta (Génesis 1-2), continuando a través de la historia de la tierra y terminando con la purificación final del planeta y su recreación. Cuando es aplicado rigurosamente, el enfoque exegético (el método histórico-gramatical e histórico-crítico) no permite una adecuada lectura de la Sagrada Escritura. Este entra en conflicto con la secuencia histórica de los textos y el desarrollo del pensamiento bíblico.

La limitación histórica del método exegético y la presuposición académica implícita de que no hay otra manera erudita disponible para estudiar la Escritura puede haber contribuido al olvido y a la sustitución de la doctrina del Santuario como la luz hermenéutica de la teología adventista.

\section{Teología bíblica}

Cuando definimos el quehacer teológico, a partir del principio de sola-tota Scriptura, no se está cuestionando la necesidad y el rol de la metodología exegética y la teología bíblica. Sin ellas, la teología adventista no puede existir. Sin embargo, debemos preguntarnos: ¿necesita el adventismo desarrollar su propia teología bíblica, o puede depender de las teologías bíblicas producidas por la erudición y otras denominaciones cristianas? Más aún, ¿las limitaciones de la metodología exegética también limitan

tion or Day of Atonement? A Response to Norman Young's Old Testament Background to Hebrews 6:19-20 Revisited", 69-88. 
los resultados que la teología bíblica puede alcanzar? ${ }^{49}$ Específicamente, ¿es la disciplina erudita de la teología bíblica el principio y el fin de nuestra búsqueda por el significado y la verdad de la Escritura? ¿Comparte su tarea de descubrir la verdad bíblica con la teología sistemática?

Naturaleza. Comencemos primero por considerar la naturaleza y la tarea de la teología bíblica. Como disciplina teológica, la naturaleza de la teología bíblica es textual porque intenta entender el texto de la Escritura. La tarea comienza primero con libros individuales y después pasa a estudiar libros por grupo de autores y finalmente a examinar el contenido general del Antiguo y del Nuevo Testamento. La meta final es reunir los grandes temas teológicos y las enseñanzas del Antiguo y Nuevo Testamento para describir la teología de la Biblia entera. ${ }^{50}$ Siendo que esta breve descripción de la naturaleza y la tarea de la teología bíblica parecen encajar con el principio

${ }^{49}$ Hasta ahora, hemos considerado solo unos pocos ejemplos de las limitaciones en el método exegético. Más adelante nos referiremos a otras limitaciones que vienen desde el lado del objetivo de la metodología exegética y la teología bíblica.

${ }^{50} E k k e h a r d t$ Müller refiere que la teología bíblica "comienza con la teología de un libro bíblico o autor, por ejemplo, la teología de Marcos. ¿Qué énfasis teológico se puede encontrar en su evangelio? ¿Cómo se desarrollan? ¿Qué quiere expresar el autor? A partir de la teología de los libros bíblicos individuales, los estudiantes de la Escritura se mueven hacia una teología del AT y a una teología del NT respectivamente y, finalmente, hacia una teología bíblica. La teología bíblica se mantiene estrictamente con el texto bíblico y no plantea asuntos que son de importancia en la actualidad, pero que no están directamente en la Biblia". Ekkehardt Müller, "Theological Thinking in the Adventist Church", DavarLogos 1:2 (2002) 129. 
de sola-tota Scriptura de la teología bíblica adventista, uno podría esperar que la erudición adventista utilice libremente teologías bíblicas producidas por la erudición u otras denominaciones cristianas.

Gerhard Hasel, erudito en Antiguo Testamento, pensaba de otro modo. En sus últimas publicaciones, propone un nuevo enfoque de la teología bíblica como disciplina erudita. La razón detrás de la propuesta de Hasel es metodológica. Él entendió correctamente que todos los modelos de la teología bíblica se construyen sobre una visión "funcional" de la Escritura. ${ }^{51}$ Por lo tanto, su propuesta gira en torno a la naturaleza y el rol de la Escritura, "entendida como la norma de la teología bíblica". ${ }^{52} \mathrm{De}$ acuerdo con Hasel, la teología bíblica no debería seguir la visión de la realidad y la Escritura que constituye la base del método histórico-crítico y de la mayoría de los enfoques de la teología bíblica. ${ }^{53}$ En cambio, el nuevo enfoque de Hasel "llama a una aproximación histórico-teológica que tenga plenamente en cuenta la autorrevelación de Dios encarnada en las Escrituras, con todas sus dimensiones de realidad". ${ }^{4}$

${ }^{51}$ Para una explicación extensa que fundamente la visión "funcional" de la Escritura, véase por ejemplo, Garrett Green, Imagining God: Theology and the Religious Imagination (San Francisco: Harper \& Row, 1989).

${ }^{52}$ Gerhard Hasel, "Proposals for a Canonical Biblical Theology", AUSS 34:1 (1996) 23.

${ }^{53}$ Para una breve introducción erudita a los varios modelos de la teología del Antiguo Testamento, véase Brevard Childs, Biblical Theology of the Old and New Testaments: Theological Reflection on the Christian Bible (Minneapolis: Fortress, 1992), 11-51.

${ }^{54}$ Hasel, "Proposals", 26. 
Hasel trabaja en el nivel donde la teología bíblica, como un quehacer intelectual, determina el significado de los textos bíblicos. Como adventista, no está satisfecho con lo que encuentra en el mundo erudito, porque los modelos de trabajo de la teología bíblica tienden a presuponer que la Escritura es el producto de la imaginación y tradición humana. ${ }^{55}$ Cuando cambiamos nuestra interpretación de la condición material del método, ${ }^{56}$ es decir, de la naturaleza de la Escritura, descubrimos que es posible un enfoque erudito diferente.

Hasel correctamente ve que la teología bíblica "tiene la tarea doble de (1) proporcionar interpretaciones resumidas de la forma final de los documentos bíblicos individuales o de los grupos de escritos, y de (2) presentar los temas longitudinales, motivos y conceptos que emergen de los materiales bíblicos". ${ }^{57}$

El centro. Al considerar este punto, debemos recordar una limitación estructural de la teología bíblica como una disciplina erudita. Llegar a una síntesis integrada de la Biblia como un todo coherente ha demostrado ser difícil, debido a la naturaleza textual de la metodología exegética. Encontrar el evasivo "centro" de la Escritura que pueda unir todas las piezas del rompecabezas bíblico ha dado origen a desacuerdos considerables entre los eruditos.

${ }^{55}$ Incluyendo al "enfoque canónico a la Teología Bíblica" que propone Childs. Hasel, "Proposals", 25.

56Sobre el lugar de la condición material en el método teológico, véase arriba y el pie de página 44 .

${ }^{57}$ Hasel, "Proposals", 29. 
La metodología exegética no es de gran utilidad a la hora de buscar el centro de la teología bíblica. Aparentemente, en esta búsqueda, los eruditos proceden por ensayo y error. Cuando encuentran un motivo bíblico importante, lo usan como centro para ver cómo funciona en la práctica.

Por su parte, en consonancia con la afirmación del principio de sola-tota Scriptura, Hasel nos recuerda que la búsqueda del centro o tema clave que pueda ayudarnos a entrelazar todas las partes de la Escritura en un todo coherente debe surgir "de los propios materiales bíblicos" ${ }^{58}$ Por esta razón, la teología bíblica no debería seguir la estructura "Dios-hombre-salvación" que los teólogos sistemáticos usan para organizar los contenidos de la Escritura. ${ }^{59}$ Además, Hasel revisa las sugerencias de diferentes temas bíblicos que los principales eruditos en Antiguo Testamento han identificado como posibles candidatos para que jueguen el papel de "centro" integrador de la teología del Antiguo Testamento. Sin embargo, él los encuentra deficientes porque "son una base demasiado estrecha sobre la cual construir una teología del AT [o bíblica], que no relegue los aspectos esenciales de la fe del AT [o bíblica] a una posición inferior y sin importancia". ${ }^{60}$

${ }^{58}$ Hasel, Old Testament Theology: Basic Issues in the Current Debate, 98.

${ }^{59}$ Ibíd.

${ }^{60}$ Algunos de los centros propuestos para la teología bíblica que Hasel revisa son "el pacto" (Eichrodt), "la elección” (Wildberger), "la comunión (Vriezen), "la promesa" (Kaiser), "el reino de Dios" (Klein), "el gobierno de Dios" (Seebass), "la santidad" (Hänel), "la experiencia" de Dios (Baab), "Dios es el Señor" (Köhler), ibíd, 99. 
De acuerdo con Hasel, "Dios es el centro dinámico unificador del $\mathrm{AT}^{\prime \prime}{ }^{61}$ Todas las otras sugerencias para el "centro" de la teología bíblica tienen en común un aspecto de Dios o su actividad en relación con el mundo o el hombre y así, inadvertidamente, señalan a Dios como centro. ${ }^{62}$ Sin embargo, cuando consideramos que Dios no solo es el centro de la teología del Antiguo Testamento, sino también, simultáneamente, el centro de la teología bíblica y de la teología sistemática, descubrimos otra limitación disciplinaria de la teología bíblica. Permítanme explicarla. Al usar la palabra "Dios", nos referimos tanto al significado de este término en los textos bíblicos como también a una realidad que opera en la vida. El primer significado pertenece al campo textual de investigación que explora la teología bíblica. El segundo pertenece al campo ontológico de la operación divina que exploran la teología fundamental y la teología sistemática. En el adventismo bíblico, tanto la teología bíblica como la teología sistemática están conectadas a través de sus datos (solatota Scriptura) como a través de su centro (Dios).

El "Dios" que es el centro de la teología bíblica no es el significado de una palabra, sino la naturaleza y la acción de un Ser real. La teología bíblica nos ayuda a entender el significado de los textos. La teología sistemática nos ayuda a usar nuestra comprensión de los textos bíblicos (que obtenemos a través de la metodología exegética) para entender la realidad y las acciones de Dios. De esta manera, la teología bíblica y sistemática se conectan a través de sus datos (la Escritura), su objeto (Dios), y sus limi-

${ }^{61}$ Ibíd., 100.

${ }^{62}$ Ibíd., 99. 
taciones metodológicas. El método de la teología bíblica nos ayuda a entender el significado de los textos a través de los cuales recibimos información sobre la realidad y las acciones de Dios. El método de la teología sistemática nos ayuda a usar las ideas trasmitidas en los textos para entender el significado de la realidad. La teología sistemática depende de la metodología exegética para entender sus datos, es decir, los textos bíblicos que revelan la realidad y la acción de Dios. La teología bíblica depende de la teología sistemática ${ }^{63}$ para entender el significado del centro que asume en la recopilación de todos los materiales de la Escritura.

Hemos comenzado esta sección preguntándonos si el adventismo bíblico puede confiar en las teologías bíblicas producidas por la erudición. Debido a que el adventismo bíblico opera a partir del principio de sola-tota Scriptura, no puede libremente adoptar los enfoques teológicos eruditos o de otras denominaciones cristianas, dado que ellos asumen que el contenido de la Escritura es producto de la imaginación humana y aplican el método histórico-crítico. La lealtad al principio de sola-tota Scriptura, entonces, requiere un replanteamiento de la teología bíblica como una disciplina erudita a lo largo de las líneas de la propuesta teológica-histórica de Hasel. Sin embargo, incluso Hasel, un firme partidario de la interpretación historicista de la profecía apocalíptica y la doctrina del Santuario, ${ }^{64}$ no

${ }^{63}$ Como veremos más adelante, tanto la teología bíblica como la teología sistemática dependen de la metodología filosófica. Ambas ayudan a determinar la clase de realidad que asumimos para el Dios de la Escritura.

${ }^{64}$ Gerhard Hasel, "The identity of 'The Saints of the Most High' in Daniel 7", Biblica 56 (1975) 173-192; The Seventy Weeks of Daniel 9:24-27 (Wash- 
requirió el rol hermenéutico de la doctrina del santuario como la visión desde la cual debemos entender el sistema completo de teología y verdad como Elena de White lo hizo. Esto nos lleva a considerar las limitaciones de la teología bíblica como un quehacer erudito.

Límites. ¿Se aplican también las limitaciones de la metodología exegética consideradas anteriormente a la teología bíblica? La respuesta a esta pregunta parece ser afirmativa. Por definición, la teología bíblica es una disciplina textual y, por ende, usa el método exegético. Por lo tanto, los límites de la metodología exegética también se aplican a la teología bíblica. Percibimos esta limitación cuando tratamos de encontrar el centro que pueda conectar los resultados analíticos de la exégesis. Por lo tanto, los límites de la metodología exegética parecen incidir en los resultados de la teología bíblica.

La teología bíblica no es el lugar donde la doctrina del Santuario nos permite ver el sistema completo de teología y de verdad. En cambio, es el lugar donde los datos bíblicos sobre la doctrina del Santuario son procesados, entendidos y conectados con el resto de los materiales bíblicos a través de los textos que hablan de Dios y sus obras. El hecho de que la erudición adventista se haya desarrollado principalmente como teología bíblica puede ser un factor que ha contribuido al olvido y reemplazo progresivo de la doctrina del Santuario como la visión hermenéutica adventista.

ington: Biblical Research Institute, 1976); "Studies in Biblical Atonement I: Continual Sacrifice, Defilement/Cleansing and Sanctuary", en The Sanctuary and the Atonement, ed. A. V. Wallenkampf, 87-114 (Washington: Review and Herald, 1980); "The 'Little Horns', the Saints, and the Sanctuary in Daniel 8", en The Sanctuary and the Atonement, 177-220. 
Si la teología bíblica es la única manera para descubrir y entender la verdad bíblica, el papel hermenéutico que la doctrina del Santuario desempeñó, en la formación del pensamiento de los primeros pioneros adventistas, no encontrará el lugar que le corresponde en la tarea erudita. La búsqueda por el centro de la teología bíblica, sin embargo, sugiere que la teología bíblica participa con la teología sistemática, en el proceso de descubrimiento de la verdad bíblica.

\section{La teología sistemática}

Hasta ahora, no hemos encontrado la disciplina o disciplinas eruditas en las que el uso que los pioneros adventistas hicieron, de la doctrina del Santuario como una visión hermenéutica que abrió la visión a un "sistema completo de verdad, conectado y armonioso" ${ }^{\prime \prime}$ pueda articularse en una forma erudita. Tal vez la idea de "sistema" pueda ser la clave para encontrar el espacio académico para la tarea hermenéutica que la doctrina del Santuario desempeña en la teología adventista. ¿Puede el sistema ayudarnos a entender mejor los materiales bíblicos y descubrir la lógica interna del pensamiento bíblico? ¿Puede la teología sistemática proporcionar el espacio erudito para el sistema completo de verdad que nuestros pioneros "vieron" en la Escritura con la "visión" hermenéutica que la doctrina del santuario abrió ante ellos? Con estas preguntas en mente, pasemos brevemente a considerar la teología sistemática.

Si la teología sistemática es el espacio erudito natural al cual pertenece el sistema completo de verdad que

${ }^{65}$ Ellen White, The Great Controversy, 423. Énfasis añadido. 
los primeros pioneros adventistas esbozaron usando la visión hermenéutica de la doctrina del santuario, tenemos mucho trabajo teológico erudito por hacer. George W. Reid señala que "nosotros, los adventistas, somos conocidos por nuestro trabajo intenso en los estudios bíblicos, a partir del cual hemos obtenido un sólido conocimiento de las enseñanzas bíblicas, dando especial atención a la escatología. Este énfasis significa que nuestro pensamiento doctrinal se tiñe con la anticipación del tiempo del fin y del regreso de Jesús. No nos hemos distinguido, sin embargo, en el campo de la teología sistemática, donde se busca integrar las verdades bíblicas en un sistema abarcante y completo". ${ }^{66}$

Aquí nos introduciremos solo brevemente dentro del campo erudito de la teología sistemática para evaluar si (1) está relacionado con el rol hermenéutico de la doctrina del Santuario experimentado en la teología adventista en sus inicios, y si (2) se necesita finalizar la tarea inconclusa de la teología adventista. Con estos objetivos en mente para esta sección, deberíamos explorar las siguientes preguntas: ¿Qué es la teología sistemática? ¿Cómo se compara y se relaciona con la teología bíblica? ¿Cómo trabaja la teología sistemática? ¿Puede la visión hermenéutica adventista, que fluye de la doctrina del Santuario, encontrar su espacio académico disciplinario en la teología sistemática? El estado inconcluso, de la teología adventista, ¿requiere un trabajo pionero en esta área de la erudición?

${ }^{66}$ George W. Reid, “Review of Norman R. Gulley, Systematic Theology: Prolegomena", Reflections: A BRI Newsletter 6 (2004) 8. Disponible en https:// adventistbiblicalresearch.org/sites/default/files/BRI\%20Newsltr\%204-04\%20 \%236.pdf (consultado: 28 de marzo, 2014). 
Estas preguntas son importantes porque la erudición del adventismo bíblico se ha desarrollado, principalmente, dentro de la disciplina de la teología bíblica. El adventismo progresivo, al contrario, se ha desarrollado tanto en la teología bíblica como en la sistemática. Ellos desarrollan la teología bíblica estudiando los textos bíblicos a partir de la perspectiva general y la guía hermenéutica del método histórico-crítico, y la teología sistemática en estrecha relación con los estudios de las tradiciones religiosas. ${ }^{67}$ Debido a que la sistemática y los estudios de las tradiciones religiosas combinan una multiplicidad de fuentes, podemos llamarlos bíblicos solo en un sentido indirecto y derivado. En contraste con este enfoque, los adventistas bíblicos necesitan considerar seriamente si el descubrimiento de la verdad bíblica requiere la metodología y la contribución de una teología sistemática bíblicamente concebida.

Naturaleza. Diferentes escuelas teológicas y tradiciones entienden la relación entre la teología bíblica y sistemática ${ }^{68}$ en diferentes formas. En el ámbito más amplio de las tradiciones clásica y moderna, Brevard

${ }^{67}$ Los estudios de las tradiciones religiosas intentan estudiar el fenómeno de la religión antes que la revelación divina. Esta disciplina crece a partir de la aplicación del método histórico-crítico a la teología. En tanto que la experiencia histórica y la imaginación de la comunidad sustituyen la comprensión divina tradicional de la revelación y la inspiración, los estudios históricos del fenómeno religioso sustituyen los estudios sistemáticos de las enseñanzas bíblicas. En los círculos adventistas progresivos, el cristianismo es también estudiado a partir de la perspectiva de los estudios de las tradiciones religiosas.

${ }^{68} \mathrm{La}$ teología "sistemática" corresponde a lo que en otras escuelas llaman "dogmática", o simplemente, "teología". 
Childs percibió la existencia de "una cortina de hierro" que separaba la teología bíblica de la sistemática. ${ }^{69}$ En la tradición bíblica evangélica y bíblica adventista, sin embargo, el problema es totalmente diferente. En lugar de la diferenciación sin relación, hay identificación sin distinción. En otras palabras, muchos adventistas bíblicos y evangélicos tienen dificultades para distinguir entre la teología bíblica y sistemática. ${ }^{70}$ Ellos no son culpables. Tradicionalmente, la erudición adventista enseñaba las doctrinas cristianas sin explicar claramente las diferencias entre la teología bíblica y la teología sistemática.

De acuerdo con el teólogo evangélico Wayne Grudem, por ejemplo, la teología sistemática estudia lo que la Biblia enseña hoy sobre cualquier tema. ${ }^{71}$ La tarea de la sistemática consiste en "coleccionar y entender todos los pasajes relevantes en la Biblia sobre diversos temas y, entonces, resumir sus enseñanzas claramente para que así, podamos conocer qué creer sobre cada tema".$^{72}$ Esta concesión prácticamente no distingue entre la tarea de la teología sistemática y la tarea de la teología bíblica. La

${ }^{69 "}$ Pronto me hice dolorosamente consciente de que una cortina de hierro separaba a la Biblia de la teología, no solo en Yale, sino en casi todo el mundo de habla inglesa. Estoy seguro de que la culpa radica en ambas disciplinas, pero la profunda desconfianza y el desinterés impidieron cualquier interacción seria". Childs, Biblical Theology, xvi.

${ }^{70}$ Para una introducción que intenta realizar una diferenciación entre ellos, véase Fernando Canale, "Is There Room for Systematics in Adentist Theology?", JATS 12:2 (2001) 110-131.

${ }^{71}$ Wayne Grudem, Systematic Theology: An Introduction to Biblical Doctrine (Leicester: Inter-Varsity Press, 1994), 21.

${ }^{72}$ Ibíd. 
noción de Millard J. Erickson de que la teología sistemática "contemporiza" [aplica a nuestro tiempo] la materia prima que se toma de la teología bíblica, ayuda incluso menos. ${ }^{73}$ Después de todo, los teólogos bíblicos no solo pretenden producir un resumen de todos los materiales bíblicos, sino también su aplicación al mundo contemporáneo. ${ }^{74}$

Bruce A. Demarest y Gordon R. Lewis enfocan el asunto con más claridad al reconocer que la teología bíblica y sistemática comparten la misma fuente de datos, la Escritura, aunque difieren en propósito y en su principio organizador. ${ }^{75}$ Sin embargo, como disciplina teológica, la teología bíblica se focaliza en entender los textos y la teología sistemática, en entender la realidad. No debemos sorprendernos entonces cuando descubrimos que también difieren respecto al principio de organización. Mientras la teología bíblica sigue la organización histórica del texto ${ }^{76}$ la teología sistemática persigue una organización "temática" y "lógica". ${ }^{77}$

${ }^{73}$ Millard J. Erickson, Christian Theology (Grand Rapids: Baker, 1990), 26.

${ }^{74}$ Este concepto también parece arraigado en el adventismo; véase, por ejemplo, Ekkehardt Müller, "Theological Thinking in the Adventist Church", 130.

${ }^{75}$ Bruce A. Demarest y Gordon R. Lewis, Integrative Theology, 2 vols. (Grand Rapids: Zondervan, 1987), 1:23.

${ }^{76}$ La teología bíblica, "con el objetivo de ser una ciencia descriptiva, se organiza en torno al desarrollo cronológico y cultural de los propios términos de un escritor bíblico, dado, sus categorías y formas de pensamiento en su contexto histórico y cultural", ibíd.

${ }^{77}$ La teología sistemática "tiene como objetivo elaborar directrices normativas para la realidad espiritual de la generación actual; organiza el material de la revelación divina temática y lógicamente, desarrollando una 
Recientemente, Norman Gulley abrió nuevos horizontes disciplinarios al producir la primera teología sistemática escrita por un adventista. ${ }^{78}$ Gulley enfoca la tarea teológica bíblica con más precisión. A la "meta" y principio organizacional" de Demarest y Lewis, Gulley añade la "guía hermenéutica de la metanarrativa bíblica", a la que también llama "cosmovisión". De acuerdo con Gulley, la metanarrativa bíblica funciona como una luz guiadora que orienta nuestra interpretación de la Escritura y de las doctrinas bíblicas. También "corrige cualquier interpretación que no se acomode a la cosmovisión bíblica" y nos guía en la comprensión de la lógica interna del pensamiento bíblico. ${ }^{79}$ La metanarrativa-cosmovisión que Gulley tiene

visión del mundo y una forma de vida coherentes y abarcantes". Ibíd. Sin embargo, estudiando atentamente a Childs, uno descubre la misma organización temática en la teología bíblica. Fritz Guy también cree que la diferencia entre la teología bíblica y sistemática gira en torno a la forma en que organizan sus materiales. Guy, Thinking Theologically, 203-219.

${ }^{78}$ George W. Reid, "Review of Norman R. Gulley, Systematic Theology: Prolegomena", 8. Actualmente ya se han publicado tres volúmenes de su trabajo sistemático.

${ }^{79 \prime}$ Una teología sistemática [explica Gulley] penetra los materiales bíblicos y alcanza la historia fundacional de la Escritura en la cual todas las otras historias se entienden mejor. Esta es la metanarrativa. Permite que cada doctrina sea comprendida dentro de la cosmovisión bíblica y, por lo tanto, corrige cualquier interpretación que no se acomoda con la cosmovisión bíblica. Esto, por lo tanto, permite que la cosmovisión bíblica sea mejor entendida y que actúe como una guía hermenéutica en una interpretación consistente de todas las doctrinas bíblicas. Provee un armazón en que las varias doctrinas bíblicas puedan ser pensadas a través de su relación interna y de su coherencia interna". Norman Gulley, Systematic Theology: Prolegomena (Berrien Springs: Andrews UP, 2003), 140. 
en mente es la "Gran Controversia" entre Dios y Satanás. ${ }^{80}$ Finalmente, Gulley correctamente, concluye: "el centro de un sistema teológico debe ser el mismo que el centro fundamental de la Escritura, si el sistema ha de ser fiel a la Escritura". ${ }^{81}$ En esta forma vemos que los centros de la teología bíblica y de la teología sistemática son idénticos.

Recordemos que de acuerdo con Hasel, el centro de la teología bíblica es Dios. Él, entonces, es el centro tanto de la teología bíblica como de la sistemática. ¿Cómo deberíamos comprender la relación de este centro y la "metanarrativa-cosmovisión" de la Gran Controversia sobre la que habla Gulley? Más aún, ¿cuál es la disciplina académica que estudia el rol y el contenido de la metanarrativa que la teología sistemática asume?

Método. Ahora estamos en condiciones de comprender mejor la forma en que opera la teología sistemática. Por lo menos tenemos "sobre la mesa", por así decirlo, algunos componentes del enfoque sistemático de la teología. La teología sistemática resulta de la interacción de varios factores, a saber, los datos, su interpretación y un objetivo. Estos constituyen tres condiciones del método teológico: la condición material, la hermenéutica y la teleológica.

Cuando enfocamos la teología cristiana a partir del principio de sola-tota Scriptura, como lo hace el adventismo bíblico, las teologías bíblica y sistemática comparten los

${ }^{80} \mathrm{Ibid}$, 713. El origen, interpretación y rol de la metanarrativa en la construcción de la teología sistemática requiere un análisis y método erudito -en otras palabras, la operación de una disciplina erudita-. Nos dirigiremos a este tema en el siguiente artículo.

${ }^{81}$ Ibíd, 146. La cursiva es del original. 
mismos datos (la Escritura) y los mismos principios hermenéuticos. ${ }^{82}$ La diferencia que requiere la existencia de dos disciplinas eruditas, por lo tanto, proviene de la condición teleológica del método. Repasando lo expuesto anteriormente, recordemos que la teología bíblica es textual (intenta entender los textos bíblicos), mientras la teología sistemática es ontológica (intenta entender la realidad). Debido a que ya hemos explorado brevemente la naturaleza textual de la teología bíblica, ahora solo debemos considerar la naturaleza ontológica de la teología sistemática.

La teología sistemática trata de entender la interrelación integral que existe entre los seres vivos y Dios como centro de la vida. Por lo tanto, no es un quehacer erudito textual sino ontológico. La diferencia en objetivos requiere una diferencia en actividades y procedimientos metodológicos. A través de su historia, la teología cristiana ha desarrollado la teología sistemática a partir de una matriz múltiple de fuentes de datos y una visión hermenéutica elaborada a partir de las enseñanzas filosóficas humanas.

El adventismo bíblico, en cambio, construye su comprensión de la realidad y la multiplicidad de la vida en relación con Dios a partir de las Escrituras como su única fuente de revelación y toma su visión hermenéutica de la doctrina del Santuario. Desde esta base disciplinaria, la teología sistemática no intenta comprender las doctrinas ${ }^{83}$

${ }^{82}$ Nos ocuparemos de los principios hermenéuticos con mayor detalle en el próximo artículo de esta serie.

${ }^{83} \mathrm{La}$ comprensión de las doctrinas no es la tarea de la teología sistemática. La teología bíblica nos ayuda a comprender las doctrinas bíblicas. La teología histórica nos ayuda a entender las doctrinas de la iglesia. La teología sistemática es el proceso a través del cual comprendemos las reali- 
de la Escritura o las creencias de la iglesia ${ }^{84}$ sino la naturaleza y la vida en relación con Dios. Mientras que la teología bíblica busca cuidadosamente las evidencias y las conexiones textuales, la teología sistemática busca las evidencias y las conexiones ontológicas presentes en los textos de la Escritura.

Cuando la meta ontológica guía la búsqueda sistemática, por el significado de la realidad, se da lugar a una interpretación y construcción teológicas mediante la interconexión de las múltiples interacciones entre los diversos seres que describe la Escritura. El centro de tales interacciones es la realidad de Dios y sus acciones. El resultado de este tipo de estudio es la concepción y formulación de las enseñanzas de la Iglesia. El método sistemático, por lo tanto, no concibe las enseñanzas cristianas como un sistema de elementos aislados y desconectados..$^{85}$ La visión

dades creadas a la luz de la Escritura y en relación con Dios (el centro de la teología). A partir de esta comprensión, la teología sistemática construye las doctrinas o enseñanzas de la iglesia.

${ }^{84}$ Esta es la visión modernista de la teología sistemática derivada de la historia de las tradiciones religiosas. La forma de "pensamiento teológico" de Fritz Guy parece corresponder a la noción moderna de la teología sistemática. "Como la interpretación de la fe, pensar teológicamente es pensar tan cuidadosa, comprensiva y creativamente como sea posible acerca del contenido, adecuación, e implicaciones de la propia vida religiosa". Guy, Thinking Theologica$l l y, 10$. El énfasis es del original. Guy propone que la teología estudia la vida religiosa. Yo propongo que estudiemos la vida a la luz de la Escritura.

${ }^{85}$ ¡Los Adventistas del Séptimo Día necesitan una teología integrada! No me malinterpreten. Las 27 creencias fundamentales del adventismo están bien definidas y son adecuadas en cuanto a lo que ellas intentan hacer como declaraciones individuales. No son las 27 creencias lo que estoy cuestionando, sino la forma en que se presentan. Para decirlo sin rodeos, las 27 
hermenéutica y el enfoque sobre la realidad (ontología) permiten a la teología sistemática descubrir la lógica interna del pensamiento cristiano. Siguiendo la manera en que Dios se interrelaciona con la realidad, como un todo, el investigador puede visualizar la lógica interna de la Escritura y las enseñanzas cristianas.

Límites. Una limitación de la teología sistemática procede de la naturaleza ontológica de su objeto. Debido a que los teólogos sistemáticos ven sus objetos a través del texto, su metodología no es adecuada para la comprensión erudita de los textos. Esta limitación lleva a distorsionar la comprensión de los datos. Como la metodología exegética permite mirar "menos" en los textos, debido a su responsabilidad con la historicidad del proceso de escritura y la dinámica de comunicación textual, la teología sistemática permite mirar "más" en el texto, porque la teología sistemática ve a partir de la perspecti-

creencias fundamentales se establecen como una lista similar a un collar en el que cada perla tiene el mismo tamaño, forma y peso". George R. Knight, "Twenty-seven Fundamentals in Search of a Theology", Ministry, February 2001, 5. Este artículo muestra la tarea inconclusa de la teología adventista que afecta a la práctica del ministerio. Desafortunadamente, Knight evita la cuestión de la integración teológica que requiere el desarrollo de la teología sistemática y se ocupa de la cuestión de la presentación de las 27 creencias fundamentales de la iglesia. Por lo tanto, su modelo para "organizar" las 27 creencias fundamentales las divide en tres áreas: Cristo [la experiencia cristiana], doctrinas [la comprensión de las enseñanzas de la Biblia], y estilo de vida [ética]. La importancia relativa de estas áreas plantea la pregunta de su integración teológica. Además, los modelos presentados suponen una teología sistemática implícita. Ya que la teología sistemática intenta comprender la realidad a partir de la perspectiva del pensamiento bíblico, esta debería revelar la forma en que las doctrinas cristianas entienden la integración de la experiencia, teoría y el quehacer. 
va de la naturaleza ontológica de sus referentes. Desafortunadamente, este enfoque responde a lo que los textos dicen de la realidad de la que el texto habla y no al texto en sí como una estructura que comunica significados. De este modo, los teólogos sistemáticos pueden llegar a "ver" en los textos bíblicos significados que no solo no son apoyados por los mismos, sino también, algunas veces, significados que contradicen lo que los textos dicen explícitamente. Esta limitación de la metodología sistemática requiere correcciones exegéticas. Por esa razón, en el adventismo bíblico la metodología sistemática debe construir sobre los resultados de la metodología exegética. Los teólogos bíblicos sistemáticos deberían usar el método exegético para procesar sus datos y deconstruir las construcciones doctrinales tradicionales. ${ }^{86}$ Por lo tanto, la teología bíblica debe ser la base y la correctora permanente de la teología sistemática bíblica.

Otra limitación de la teología sistemática procede del lado de sus presuposiciones hermenéuticas. Así como los teólogos bíblicos, los teólogos sistemáticos asumen la interpretación de las presuposiciones hermenéuticas. Las metodologías bíblica y sistemática no generan la interpretación de la metodología y los principios hermenéuticos que ellas utilizan. Tradicionalmente, las disciplinas filosóficas de la ontología y la epistemología han generado la interpretación de los principios hermenéuticos que guían a los teólogos en la construcción de las doctrinas cristianas. En el siguiente artículo, de esta

${ }^{86}$ Sobre el rol de la teología bíblica en la deconstrucción teológica véase Fernando Canale,"Deconstrucción y teología: una propuesta metodológica", DavarLogos 1:1 (2002) 3-26. 
serie, argumentaré que los teólogos no deberían dejar a los filósofos la interpretación de esta área fundamental de la teología cristiana. En cambio, deberían crear una nueva disciplina erudita independiente que se ocupe en criticar e interpretar la metodología teológica y sus condiciones hermenéuticas.

La visión hermenéutica. En las tradiciones clásica y moderna/posmoderna de la teología cristiana, la luz hermenéutica que dirigió las interpretaciones y construcciones teológicas viene de algunas ideas filosóficas o científicas. ${ }^{87}$ En el adventismo bíblico, sin embargo, la luz hermenéutica que guía a la teología bíblica y a la teología sistemática en sus interpretaciones y construcciones fluye de la doctrina del Santuario. ${ }^{88}$

Permítame brevemente ejemplificar la forma en que la doctrina del Santuario funciona como la visión her-

${ }^{87}$ Por ejemplo, considere el propósito de la metodología de la teología escolástica: “Cuando el material dogmático con la ayuda del método histórico ha sido derivado de sus fuentes, otra trascendental tarea aguarda al teólogo: la apreciación filosófica, la examinación especulativa y la elucidación del material traído a la luz. Este es el propósito del método 'escolástico' del cual la 'teología escolástica' toma su nombre”. J. Pohle, “Dogmatic Theology", in The Catholic Encyclopedia, disponible en http:/ / www. newadvent.org/cathen/14580a.htm (consultado el 28 de marzo, 2014). Esta "apreciación filosófica" del material (datos) traído a la luz corresponde a la visión hermenéutica o al papel que la doctrina del Santuario juega en el adventismo bíblico.

${ }^{88}$ Norman Gulley habla de una "metanarrativa" o "cosmovisión" como la luz hermenéutica que guía a la teología sistemática. Me referiré a la forma en que la metanarrativa bíblica de la Gran Controversia se relaciona con la doctrina del Santuario como una luz hermenéutica en el siguiente artículo. 
menéutica que guía la interpretación de la Escritura y la construcción de las enseñanzas cristianas. Cuando leemos la Escritura, con el objetivo ontológico de la teología sistemática, intentamos entender la doctrina del Santuario como una realidad. ${ }^{89}$ Cuando los pioneros adventistas estudiaron la doctrina bíblica del Santuario, entendieron su realidad celestial históricamente. Esta interpretación se apartó decididamente de las lecturas clásica y moderna que entendían que las realidades celestiales eran atemporales y espirituales..$^{90}$ La realidad temporal histórica del Santuario celestial desempeñó un rol hermenéutico decisivo en la comprensión de Daniel 8:14. Después de la muerte de Cristo, el santuario del Antiguo Testamento encontró su antitipo. El libro de Hebreos y Apocalipsis muestran que después de la resurrección de Cristo, la acción redentora de Dios fluye del Santuario celestial. Por lo tanto, para los adventistas resultó obvio que la purificación del Santuario ocurre ontológicamente no en una realidad espiritual ya existente en el ser eterno de Dios o en su muerte en la cruz, sino en un nuevo acto histórico redentor de Dios que se está realizado realmente en favor de los santos en el cielo desde el año 1844. Esta comprensión del Santuario no tiene solo implicaciones proféticas, sino también teológicas. Lleva a los adventistas a comprender la doctrina de la salvación como un proceso histórico todavía en progreso.

${ }^{89}$ Como veremos en el siguiente artículo, el referente ontológico (la realidad en la vida) del pensamiento bíblico se puede interpretar en formas que difieren ampliamente.

${ }^{90}$ Para una breve introducción véase Fernando L. Canale, "Philosophical Foundations and the Biblical Sanctuary", AUSS 36:2 (1998) 183-206. 


\section{Resumen}

Durante los últimos 60 años, la teología adventista ha entrado en un nuevo campo de juego, donde los teólogos emprenden el estudio de la Escritura y las doctrinas cristianas, a través del uso de reglas cuidadosamente definidas (metodología). ${ }^{91}$ Los teólogos dividen la tarea teológica en disciplinas. Debido a que el adventismo está fuertemente comprometido con el principio de sola Scriptura, la disciplina erudita de la teología bíblica ha atraído la creatividad y el esfuerzo de la mayoría de los teólogos adventistas. Pronto, desacuerdos sobre la metodología exegética dividieron a la erudición bíblica adventista. Por un lado, los adventistas evangélicos y progresivos decidieron usar "una versión modificada" del método histórico-crítico. ${ }^{92}$ Por otro lado, los adventistas bíblicos están utilizando implícitamente una metodología alternativa a las metodologías histórico-gramatical e históricocrítica a la que Gerhard Hasel llamó "teología bíblica" y Richard Davidson llamó "histórica-bíblica". ${ }^{93}$ A medida

${ }^{91}$ Discutiremos la metodología teológica en el siguiente artículo. Véase también Fernando Canale, "Evolution, Theology, and Method, part 3: Evolution and Adventist Theology", AUSS 42:1 (2004) 5-48.

${ }^{92}$ No tengo conocimiento de ningún estudio adventista sobre metodología exegética que aclare la naturaleza de las "modificaciones" que el adventismo evangélico y el adventismo regresivo efectuaron en el método histórico-crítico. El reemplazo del sesgo naturalista del empirismo científico con la trascendencia divina y la inspiración de la Escritura, como Gladson sugiere, no modifica el método histórico-crítico, sino que muestra las razones por las cuales su aplicación no contradice los sistemas de teología clásica y protestante.

${ }^{93}$ Véase en este artículo el pie de página 38. 
que la erudición adventista vaya desarrollando con más amplitud y precisión una metodología exegética alternativa basada sobre el principio de la sola Scriptura, nuevas generaciones de eruditos adventistas podrán usarla para "navegar" mejor en el mundo erudito y para unir la teología de la iglesia y compartirla en los niveles académicos más sofisticados. Dios puede usar estos esfuerzos para difundir la revolución teológica adventista, a través de las barreras denominacionales.

La metodología exegética tiene limitaciones. Primero, requiere del uso de presuposiciones. Necesitamos estudiar, evaluar y seleccionar las presuposiciones involucradas en la metodología exegética cuidadosamente. La teología fundamental provee las herramientas y el espacio disciplinario para tales tareas. Segundo, la naturaleza textual de los datos que intenta entender también limita la metodología exegética. Debido a que la metodología exegética está estrechamente vinculada a la historia de la generación del texto, no puede explorar la historia de la salvación que los textos revelan. La teología sistemática provee las herramientas y el espacio disciplinario para dicha tarea.

Las fuentes extra-bíblicas, a partir de las cuales todas las teologías bíblicas definen las condiciones de la metodología exegética, han dejado la puerta abierta para un nuevo enfoque metodológico que construya sobre la interpretación bíblica de las condiciones del método. Este enfoque es coherente con la teología adventista bíblica a la que apoya sin reservas. Sin embargo, la teología bíblica requiere un centro a partir del cual se pueda conectar la vasta variedad de asuntos, historias y enseñanzas que encontramos en los textos bíblicos. La erudición exegética todavía no ha llegado a un acuerdo con respecto a qué 
motivo bíblico debería ser el centro. Hasel, correctamente, descarta todos los motivos bíblicos y elige a Dios como el centro de la teología bíblica. Al vincular los centros de la teología bíblica y sistemática, implícitamente reconocemos sus limitaciones disciplinarias estructurales y su interdependencia. Por lo tanto, la adecuada expresión de la doctrina del Santuario, como una visión hermenéutica de un sistema completo y armonioso de verdad, requiere las contribuciones de nuevos enfoques para la teología bíblica y la teología sistemática.

La teología sistemática intenta entender la realidad y cómo esta se relaciona con Dios. En el adventismo bíblico, la teología sistemática difiere de la teología bíblica con respecto a su meta. Mientras la meta de la primera es ontológica (naturaleza y vida y cómo ellas se relacionan con Dios), la última, es textual. La teología sistemática bíblica explora la lógica interna del pensamiento bíblico, al descubrir la interconexión de los eventos relacionados e interpretados en la Escritura. Una tarea tan ambiciosa requiere la guía hermenéutica de amplias presuposiciones hermenéuticas sobre la realidad a las que Gulley agrupa bajo las etiquetas de "meta-narrativa" y "cosmovisión". La tarea de la teología sistemática revela la presencia y orientación hermenéutica de ideas generales y abarcantes sobre la realidad (condiciones hermenéuticas de método teológico) que operan a lo largo de todas las tradiciones y escuelas de teología. La tradición erudita cristiana ha interpretado estas ideas abarcantes usando como luz hermenéutica a las ontologías filosóficas y científicas. Desde la perspectiva abierta por estas ideas generales, los teólogos cristianos han desarrollado sus interpretaciones de la Escritura y construido las enseñanzas del cristianismo. Siguiendo otro camino, el adventismo bíblico 
interpreta las mismas ideas abarcantes y directrices a partir de la Escritura. En este nivel fundamental, la doctrina del Santuario proporciona la luz hermenéutica que nos guía tanto al interpretar estas ideas generales y abarcantes (condición hermenéutica del método teológico) como al entender y formular el sistema completo y armonioso de la teología cristiana.

Si bien la función hermenéutica de la visión del Santuario de los primeros pioneros adventistas encuentra su espacio erudito en el ámbito de la teología fundamental, el sistema completo de verdad conectado y armonioso encuentra su espacio erudito en la teología sistemática. Como sugerimos de paso, la misma visión hermenéutica también funciona, aunque de una manera más implícita que explícita, en la teología bíblica. Consideraremos la función de la doctrina del Santuario en la teología fundamental en el siguiente artículo de esta serie.

\section{Conclusión}

Nuestra breve reseña de las disciplinas básicas eruditas, involucradas en la tarea de hacer teología cristiana en el nivel académico de las universidades, nos permite responder parcialmente la pregunta que enmarcó nuestra investigación.

El adventismo evangélico y el adventismo progresivo no están en lo correcto cuando argumentan que un trabajo erudito honesto requiere la adopción de metodologías, tradiciones y ciencias universalmente aceptadas. Debido a que el método involucra condiciones que podemos interpretar en diferentes formas, la erudición adventista no necesita aceptar los enfoques académicos y tradicionales para la construcción teológica. Por el con- 
trario, el adventismo está comprometido con el principio de sola-tota Scriptura que requiere el abandono de las fuentes múltiples tradicionales de la matriz teológica y de la guía hermenéutica trazada por las ontologías filosófica y científica. El adventismo bíblico no está forzado a seguir las indicaciones del adventismo evangélico y progresivo para ser honestos intelectualmente. Sin embargo, debe prestar atención a las preguntas metodológicas, tradicionales, filosóficas y científicas para criticarlas y fundamentar, formular y explicar sus posiciones teológicas en el sofisticado mundo de la erudición.

El adventismo bíblico puede ser "honesto intelectualmente" y al mismo tiempo hacer teología erudita a partir de la luz hermenéutica que irradia de la doctrina del Santuario y, la interpretación historicista de la profecía, como lo hicieron los pioneros. Esto requiere una extensa labor académica que el adventismo todavía no ha producido. Para ver el sistema completo de teología y de verdad que los pioneros vieron, en el nivel académico de la investigación erudita, el adventismo necesita desarrollar sus propios enfoques eruditos para la teología fundamental, la teología bíblica y la teología sistemática. La teología bíblica tiene las herramientas para entender los textos bíblicos. La teología sistemática tiene las herramientas para descubrir y formular el sistema bíblico de verdad. La teología fundamental tiene las herramientas para descubrir y formular la visión hermenéutica y las condiciones metodológicas que asumen la teología bíblica y la teología sistemática. La luz hermenéutica de la doctrina del Santuario es primordial para estas herramientas. Los adventistas contemporáneos necesitan incorporar esto en las condiciones hermenéuticas del mé- 
todo teológico. La formulación de un enfoque adventista para la teología bíblica y la teología sistemática, por lo tanto, reclama un innovador trabajo académico en estas áreas. A partir de esta visión hermenéutica, el adventismo será capaz de ver el sistema completo y armonioso de verdad bíblica y formularla como una alternativa académica viable. Tornaremos nuestra atención a la teología fundamental en el siguiente artículo de esta serie. 